\title{
U.S. Department of Energy/ Westinghouse Hanford Company ARECO Cesium Transportation Plan
}

\author{
E. P. Clements
}

Date Published

July 1996

Prepared for the U.S. Department of Energy Office of Environmental Restoration and Waste Management

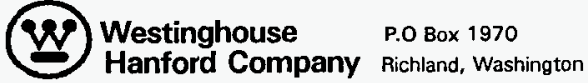

Management and Operations Contractor for the

U.S. Department of Energy under Contract DE-AC06-87RL10930 
ThE THE MTENTONALY LIF BLANK. 
LEGAL DISCLAIMER

This report was prepared as an account of work sponsored by an agency of the United States Government. Neither the United States Government nor any agency thereof, nor any of their emplovees, nor any of their contractors, subcontractors or their employees, makes any warranty, express or implied, or assumes any legal liability or responsibility for the accuracy, completeness, or any third party's use or the results of auch use of any information, apparatus, product, or process disciosed, or represents that its use would not infringe privately owned rights. Reference herein to any specific commercial product, process, or service by trede name, trademark, manufacturer, or otherwise, does not necessarily constitute or imply its endersement, recommendation, or favoring by the United States Government or any agency thereof or its contractors or subcontractors. The views and opinions of euthors expressed herein do not necessarily state or reflect those of the United States Goverrment or any agency thereof.

This report has been reproduced from the best available copv. Available in paper copy and microfiche.

Available to the U.S. Department of Energy and its contractors from

Office of Scientific and Technical Information

P.O. Box 62

Oak Ridge, TN 37831

(615) $576-8401$

Available to the public from the U.S. Department of Commerce National Technical Information Service

5285 Port Royal Road

Springfield, VA 22161

(703) $487-4650$

Printed in the United Stetes of Americe

DISCLM-1.CHP (1-91) 
THIS PAGE INTENTIONALLY LEFT BLANK. 


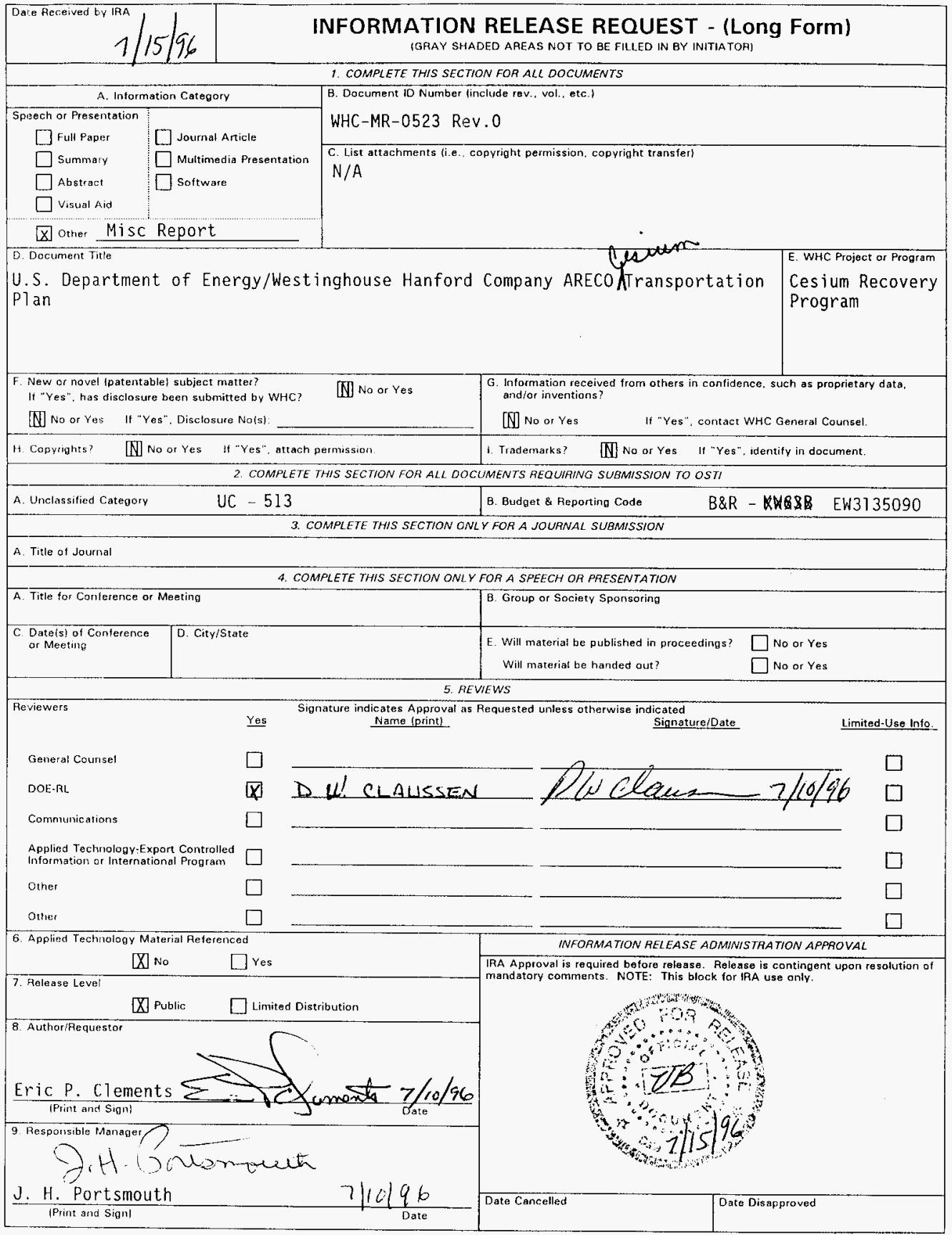


THIS PAGEINTEMTIONALLY LEFT BLANK. 
WHC-MR-0523 Rev.0

Document 10 Number

10. LEGENDS/NOTICES/MARKINGS (Required by WHC-CM-3-4 or Reviewer). Reviewer indicates applicable markings to be affixed or removed.

Affix Bemove Initials

Applied Technology

Availability - OSTI

Availability - ESTSC

Availability - NTIS

Busines:s-Sensitive Information

Computer Software Notica

Copyright License Notice

Export Controlled information

Legal Disclaimer

Limited Disclosure $\square \quad \square \quad \square$

$\square \quad \square$

$\forall \square$ प.

$\square \square$

$\square \square$

$\square \quad \square$

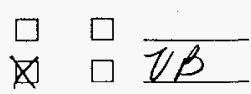

$\square \quad \square$
Official Use Only

Patent Status

Predecisional Information

Programmatic Notice

Proprietary Information

Purpose and Use

Thesis/Dissertation

Trademark Disclaimer

Other:
Affix Remove Initials

$\square \quad \square$

$\square \quad \square$

$\square \quad \square$

$\square \quad \square$

$\square \quad \square$

$\square \quad \square$

$\square \quad \square$

$\square \quad \square$

$\square \quad \square$
11. MANDATORY COMMENTS \{ List only mandatory comments here Alf other comments shall be made on the doctiment and returned to the author.)

12. ADOITIONAL INFORMATION/COMMENTS:

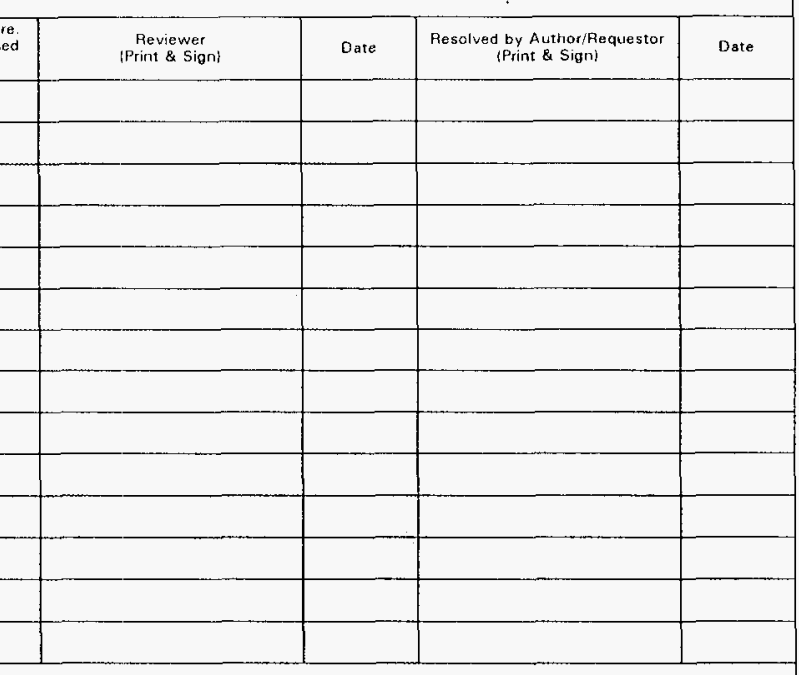

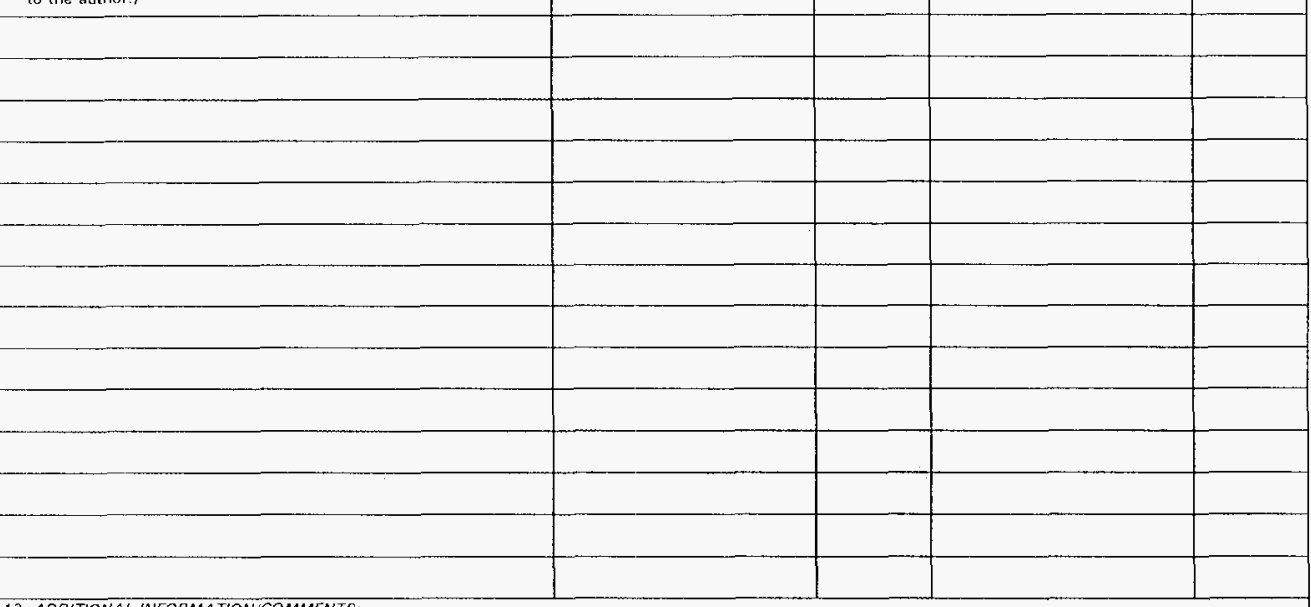

.

:


THS PAGE HTENTIONALLY LEFT BLANK. 


\section{RELEASE AUTHORIZATION}

\begin{tabular}{ll}
$\begin{array}{l}\text { Document } \\
\text { Number: }\end{array}$ & WHC-MR-0523, Rev. 0 \\
\hline $\begin{array}{l}\text { Document } \\
\text { Title: }\end{array}$ & $\begin{array}{l}\text { U.S. Department of Energy/Westinghouse Hanford } \\
\text { Company ARECO Transportation Plan }\end{array}$ \\
\hline
\end{tabular}

Release Date: $07 / 15 / 96$

This document was reviewed following the procedures described in WHC-CM-3-4 and is:

APPROVED FOR PUBLIC RELEASE

พHC Information Release Administration specialist:
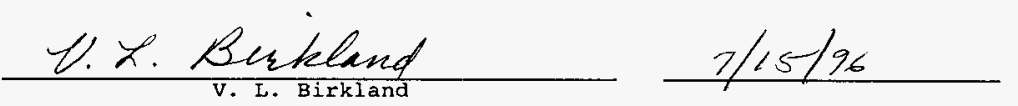

$\mathrm{UC}-2000$

KEYWORDS: Cesium Recovery, Hazardous Waste, Transportation, Safety 
THS AOE MIIUTONALLY LEFTBLANK. 


$$
\text { WHe-me-0523, Reur } 0
$$

\section{U.S. DEPARTMENT OF ENERGY/WESTINGHOUSE HANFORD COMPANY ARECO CESIUM TRANSPORTATION PLAN}


This page intentionally left blank. 
CESIUM TRANSPORTATION PLAN Rev. O June 1996 WHC $-M R-0.523, R E V .0$

\section{CONTENTS}

1.0 INTRODUCTION . . . . . . . . . . . . . . . . . . . . . . . . . 1

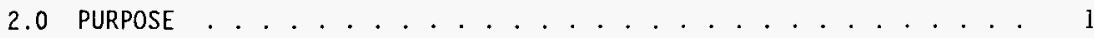

3.0 PROGRAM PLAN . . . . . . . . . . . . . . . . . . . . . . . . . I

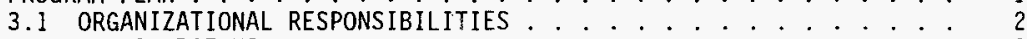

3.1.1 DOE-HQ . . . . . . . . . . . . . . . . . . . . 2

3.1.2 TRANSCOM Control Center .............. . . 2

3.1.3 DOE, Richland Operations Office/WHC . . . . . . . . . 2

3.1 .4 ARECO ................... . . . 3

3.1.5 State of Virginia . . . . . . . . . . . . . . . 4

3.1 .6 U.S. NRC ....................... . 4

3.1.7 Corridor States/Tribes . . . . . . . . . . . . . 4

3.1 .8 TSMT .................... . . . 5

3.2 SHIPMENT SCHEDULE . . . . . . . . . . . . . . . . . . . . . . . . . 6

3.3 ADVANCE INFORMATION/TRACKING OF SHIPMENT . . . . . . . . . . . . . 7

3.4 EMERGENCY CONSIDERATIONS . . . . . . . . . . . . . . . . . . . . 7

3.4.1 Emergency Preparedness . . . . . . . . . . . . . . . . . 8

3.4.2 Notifications . . . . . . . . . . . . . . . . 8

3.4.3 Emergency Response . . . . . . . . . . . . . . . . . . 8

3.4.4 Recovery . . . . . . . . . . . . . . . . . . . . 9

3.4.5 Cleanup and Site Restoration . . . . . . . . . . 10

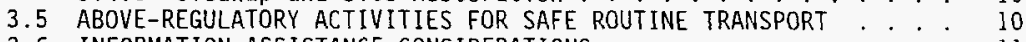

3.6 INFORMATION ASSISTANCE CONSIDERATIONS . . . . . . . . . . . . . . 11

4.0 PACKAGING DESCRIPTION . . . . . . . . . . . . . . . . . . . 11

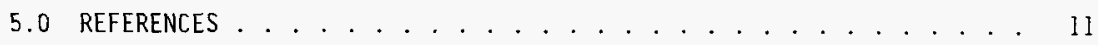

APPENDIX A: TSMT HAZARDOUS WASTE AND RADIOACTIVE MATERIALS DRIVER'S

TRAINING . . . . . . . . . . . . . . . . . . . . A $\mathrm{A}-1$

APPENDIX B: TSMT/OHM EMERGENCY RESPONSE/CONTINGENCY PLAN AND CS CASK

RECOVERY GUIDE ................... . . . B-1

APPENDIX C: GUIDE 1641996 EMERGENCY RESPONSE GUIDEBOOK . . . . . . . . . C-I

APPENDIX D: LYNCHBURG, VA-HANFORD, WA HRCQ ROUTE MAP . . . . . . . . . . D-1

APPENDIX E: STATE/CONFEDERATE TRIBES OF THE UMATILLA INDIAN RESERVATIONS (CTUIR) CONTACTS FOR EMERGENCY CONDITIONS . . . . . . . . E-]

APPENDIX F: STATE/CTUIR SUMMER SEASON/ROAD CONDITIONS POLICY . . . . . . F-1

APPENDIX G: SAFE-PARKING CRITERIA FOR ${ }^{137} \mathrm{CS}$ SHIPMENTS . . . . . . . G-1 


\section{LIST OF FIGURES}

1 Expected Typical Shipment Schedule (Working Days) . . . . . . . . . 6 
WHC - $m R-0523$ REVO.

CESIUM TRANSPORTATION PLAN Rev. O June 1996

\section{LIST OF TERMS}

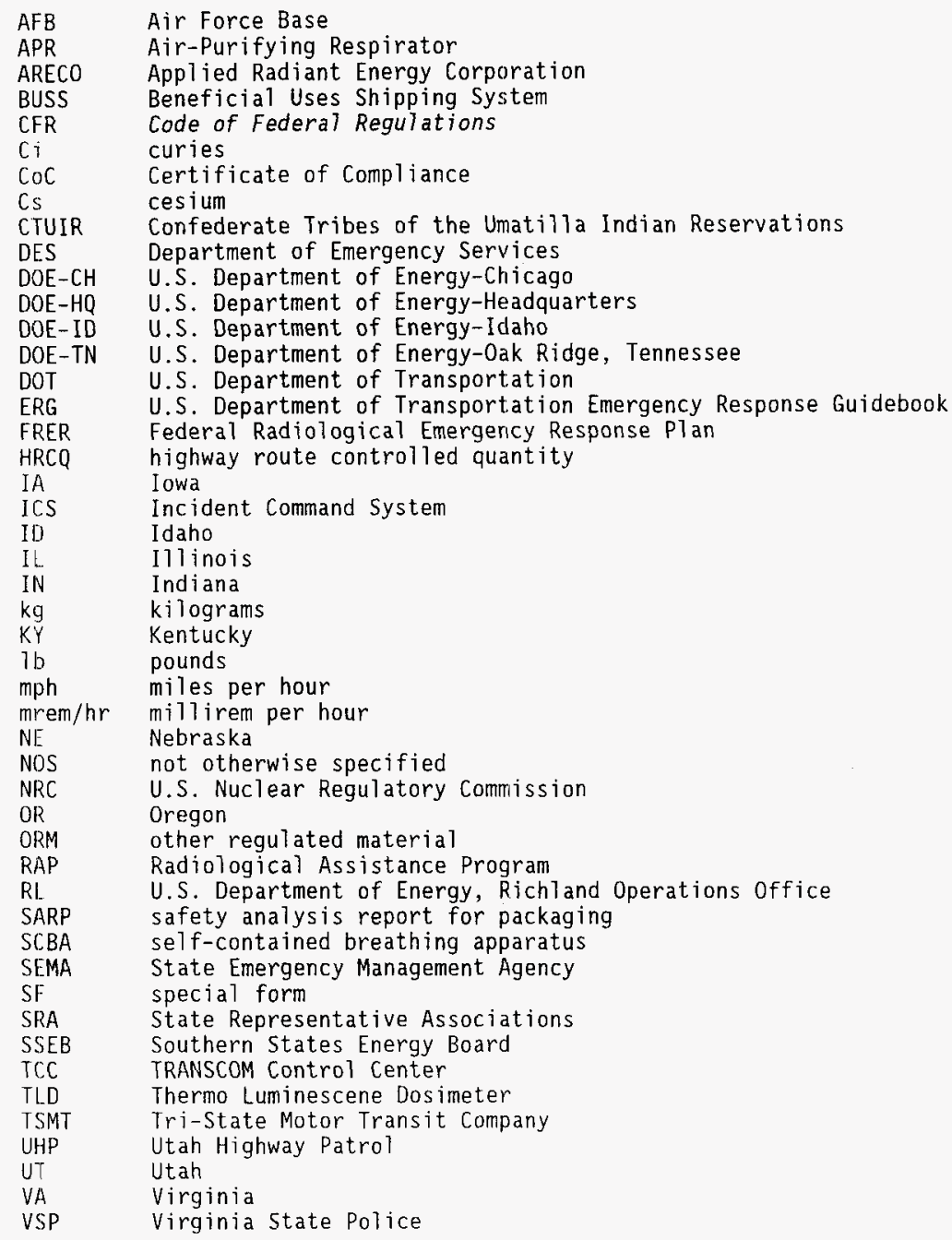




\title{
LIST OF TERMS (Continued)
}

\author{
WV West Virginia \\ WA Washington \\ WESF Waste Encapsulation and Storage Facility \\ WGA Western Governors' Association \\ WHC Westinghouse Hanford Company \\ WSP Washington State Patrol \\ WY Wyoming
}




\subsection{INTRODUCTION}

The U.S. Department of Energy (DOE) is committed to the safe, efficient, and cost-effective transportation of all materials that support its various programs and activities. DOE strives to ensure that hazardous materials (particularly radioactive), hazardous substances, and hazardous mixed waste are handled and transported in compliance with all applicable federal, state, tribal, and local rules and regulations. This plan outlines the activities and responsibilities of DOE and other agencies that will be followed to conclude a significant movement of radioactive cesium (Cs) chloride capsules in a safe and uneventful manner.

DOE-Headquarters (DOE-HQ) has directed that $C S$ capsules manufactured at the Waste Encapsulation and Storage Facility (WESF) be returned to WESF, located at DOE's Hanford Site in southeast Washington State. Currently, there are $25 \mathrm{Cs}$ capsules at the Applied Radiant Energy Corporation (ARECO) facility utilized for the polymerization of wood products in Lynchburg, Virginia, that requires removal as part of the overall Cs capsule return effort.

This plan has been prepared in cooperation with member states of the Western Governors' Association (WGA) and the Southern States Energy Board (SSEB); the Council of State Governments Midwestern Office; and the Confederated Tribes of the Umatilla Indian Reservations, through whose jurisdictions these shipments will pass, and is an example of DOE-HQ's commitment to early coordination and substantive involvement in its decision-making processes.

\subsection{PURPOSE}

This transportation $\mathrm{plan}$ identifies responsibilities, requirements, and procedures to ensure the success of the capsule return program. The plan summarizes transportation activities, organizational responsibilities, emergency preparedness guidelines, and other methods for achieving safe transport.

\subsection{PROGRAM PLAN}

The handling, packaging, and transport of Cs capsules will be accomplished through a system of sequential steps resulting in the removal of all CS capsules from ARECO. Source handling and capsule loading activities wi 71 be performed by the Westinghouse Hanford Company (WHC), the prime contractor at Hanford. The selected carrier for this campaign is the Tri-State Motor Transit Company (TSMT). The transportation plan details roles and responsibilities for these and the other organizations listed below. 
$W H C-M K-0523, \pi E \% C$

CESIUNI TRANSPORTATION PILAN

Rev. 0 June 1996

\subsection{ORGANIZATIONAL RESPONSIBILITIES}

\subsubsection{DOE-HQ}

DOE-HQ sets overall policy for transportation, resolves policy questions, issues guidance, and provides information for use in transportation activities. DOE can also provide an emergency response team, including personnel with package operation expertise, in the event of a transportation incident. DOE will provide advance information regarding the $C$ s shipments to involved organizations and agencies. DOE has committed to providing corridor states with appropriate technical assistance to help prepare for these shipments.

\subsubsection{TRANSCOM Control Center}

The handling of transport communications, satellite shipment location/tracking, weather and road conditions/updates, state/tribal informational update exchange, transport emergency response communication/location wiTl be handled by the TRANSCOM Control Center (TCC). This exchange of information by all parties involved is handled through the TCC and relayed to the carrier, DOE, stakeholders, states, tribal, and emergency responders (if required) designates as described further in this section.

\subsubsection{DOE, Richland Operations office/WHC}

DOE, Richland Operations office (RL) is responsible for overall program management for the transfer of Cs capsules from the ARECO facility to Hanford. RL is the shipper of record, with WHC acting as agent, and both RL and WHC are responsible for conducting shipping activities in compliance with the Beneficial Uses Shipping System Cask Safety Analys is Report for Packaging (SARP), DOE/U.S. Nuclear Regulatory Commission (NRC) Certificate of Compliance $(C O C)$, and applicable federal, state, and local requirements and the conditions described in this transportation plan. As agent for RL, WHC has the following specific responsibilities:

- WHC WESF Engineering is responsible for determining the schedule for loading and shipping of capsules. This determination witl be based upon such factors as WESF's ability to receive Cs capsules, testing of the capsules, consulting with WHC Transportation and Packaging on predicted weather conditions, and existing road conditions along the route. WHC will notify ARECO, scheduled support contractors, and TSMT of the intent to load and ship capsules.

- WHC WESF Engineering is responsible for pre-loading activities, including preparing and testing of loading equipment, radiological surveys of the empty incoming packages and associated equipment, and support personnel. 
- WHC Transportation and Packaging is responsible for providing shipment schedules and updates to TCC. This information, which includes the bill of lading, will be submitted in accordance with procedures found in the TRANSCOM Shipper and Receiver Users' Manual.

- WHC Transportation and Packaging will ensure that radiological limits for the package are in compliance with the U.S. Department of Transportation (DOT) 49 Code of Federal Regulations (CFR) requirements, the package's NRC and/or DOE COC and SARP, through surveys performed on loaded packages using qualified, trained personnel, calibrated equipment, and approved procedures.

- Special form (SF) testing of the capsules at the ARECO facility will be conducted prior to initiating capsule shipments. Testing will consist of a visual inspection, a ring-gauge test and a clunk test.

- WHC Transportation and Packaging will ensure that all shipping documentation is properly completed, signed, and certified, and that all required labeling, marking, and placarding is applied per 49 CFR requirements before release of the shipment from the ARECO facility. WHC will verify TSMT commercial drivers' licenses and state permits (as necessary) and will ensure that the load is properly secured.

- WHC Transportation and Packaging will provide TSMT drivers with a driver information packet containing copies of the bill of lading (shipping paper), the highway route controlled quantity (HRCQ) shipment route plan (map), and appropriate emergency response information, as well as driver's and exclusive use instructions required for HRCQ shipment, before a shipment is dispatched from the ARECO facility. This information packet will be provided to law enforcement personnel to complete required sign-off by the inspecting state authority if required.

- WHC WESF Engineering and Transportation and Packaging is responsible for following requirements of the SARP, COC, and associated operating procedures during the capsule loading, examination, unioading, and storage process.

- WHC will supply an escort vehicle for shipments along the entire transportation route. This escort will have health physics/Beneficial Uses Shipping System (BUSS) cask technical expertise and wiTl be available as a resource (upon request) for an incident commander in the event of a transportation incident. Only loaded shipments (i.e., shipments from ARECO to Hanford) will be escorted.

\subsubsection{ARECO}

ARECO will provide information/data, NRC nuclear materials 1 icense modifications, and facility personnel expertise necessary for WHC to safely and economically recover the Cs capsules from its Lynchburg facility. Such information and support will be used solely for the purpose of Cs capsule recovery activities. ARECO will provide facility access to WHC during capsule recovery activities. 


\section{1 .5 State of Virginia}

The Virginia DOT maintains the lease agreement (property and building) with ARECO and will be responsible for approving any facility modifications required for the return of the capsules to Hanford.

The Virginia State Police (VSP) will inspect the shipment and vehicle using the "Recommended National Procedures for the Enhanced Safety Inspection of Commercial Highway Vehicles Transporting Transuranics, Spent Fuel, and High-Level Radioactive Waste" (hereinafter referred to as the enhanced North American Standards) prior to release from the ARECO facility. This inspection to the enhanced North American Standards is for the purpose of continued testing of the standards, and will include application of the related out-of-service criteria.

Enforcement actions (citations and fines) for violations discovered during inspections will be applied based on existing state laws and regulations.

\section{1 .6 U.S. NRC}

The NRC, Region II, has issued a Radioactive Material License to ARECO for the storage, testing, preparation, and packaging for the return of the $C S$ capsules to Hanford. The NRC will approve the removal of $C s$ capsules from the ARECO facility by amending their current NRC Nuclear Material License (3.1.4).

\subsubsection{Corridor States/Tribes}

The states of Virginia, West Virginia, Kentucky, Indiana, Illinois, Iowa, Nebraska, Wyoming, Utah, Idaho, Oregon, Washington, and the Confederated Tribes of the Umatilla Indian Reservation have responsibility for establishing procedures and providing personnel and equipment to take charge of emergency situations, if necessary.

- Corridor states may exercise responsibility for vehicle and equipment inspections; these inspections, if conducted, will be in accordance with the enhanced North American Standards, and will include application of the related out-of-service criteria. Enforcement actions (citations and fines) for violations discovered during inspections will be applied based on existing state laws and regulations.

- Corridor states will designate a central point of contact to provide current weather and road conditions along the route to the TCC. At this time, the ARECO Cs capsule recovery transportation is scheduled to occur between May 1 through September 30, 1996. Winter Season Bad Weather Policy is not currently addressed in this transportation plan. If, for any reason, it is necessary to transport between the months of october through April, this transportation plan will be revised to include Winter Season Bad Weather Policy prior to any winter season shipment. 


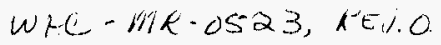

CESIUM TRANSPORTATION PIAN Rev. O June 1996

- Corridor states and/or the designated carrier drivers have the authority to hajt or delay a shipment if weather or road conditions are unacceptable.

- Once a vehicle has been directed into a safe-parking area, the stateand/or tribal-designated authority will provide clearance to continue travel. The corridor states are responsible for developing procedures within their state for designating authority for ordering shipments to stop or to proceed.

- States are responsible for notifying TCC of any conditions that may affect a shipment crossing their jurisdiction. States should notify TCC, TCC should notify WHC and TSMT. States will notify TCC through TRANSCOM. This notification can happen at any time a shipment is scheduled for departure. TCC should be the central point of contact for the states for a 71 notifications.

\section{1 .8 TSMT}

TSMT is responsible for safely transporting the Cs capsule shipments to Hanford. This responsibility includes obtaining required state permits, using the designated HRCQ route, and arranging for vehicle inspections in cooperation with WHC Transportation by VSP at origin. TSMT will work with other states and tribes to arrange inspections as required.

- TSMT is responsible for providing emergency recovery personnel, equipment (including repair/replacement of tractor or trailer if required) and procedures in the event of a highway incident as described in Section 3.4 of this document (TSMT procedures are found in Appendix B).

- TSMT will ensure that driver training requirements have been met, that vehicles meet the enhanced North American Standard inspection requirements and that the vehicles are "defect free" before and throughout the shipment.

- TSMT and/or WHC Transportation and Packaging will notify the VSP to arrange for tractor and trailer inspections and/or reinspection of the vehicle if shipment is delayed for more than 72 hours.

- TSMT drivers will inspect the vehicle and security of the load every two hours or 100 miles, whichever occurs first. TSMT will maintain communications via TRANSCOM from dispatch at ARECO to receipt at WESF. TSMT drivers will implement backup communications procedures in the event of TRANSCOM system failure as specified in TRANSCOM operating procedures. TSMT dispatchers trained on Cs transportation protocol as outlined in this transportation plan, will monitor the tractor/BUSS cask's progress on a 24-hour basis while en route to Hanford. TSMT will notify WHC

Transportation and Packaging of any delays or problems that occur while in transit.

- TSMT is responsible for compliance with all applicable federal, state, tribal, and local transportation requirements and the conditions described in this transportation plan. 


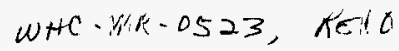

CESIUM TRANSPORTATION PLAII Rev. 0 June 1996

- TSMT will ensure eiffective communi iation with the drivers on all extraordinary everts involving the shipments, including external public relations/affairs events that have potential impact upon the shipment.

- TSMT will be responsible for obtaining appropriate state permits prior to the first shipment.

\subsection{SHIPMENT SCHEDULE}

A "shipment" as referred to in this plan is defined as the period from notification of loading the packaging to the return of the empty packaging for reloading.

Recovery of a 17 capsules from ARECO will require two shipments lasting approximately 22 days each.

Figure 1. Expected Typical Shipment Schedule (Working Days).

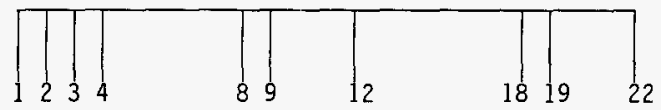

Day 1. Notification to participants (carrier, ARECO, states and tribes) through TRANSCOM of intent to start shipping campaign. WHC personnel travels to ARECO.

Day 2-3. WHC arrives at ARECO to start preparation activities.

Day 4-8. Begin cask preparation, capsule loading, and cask assembly activities at ARECO.

Day 9. Departure of vehicle with loaded package from AREC0 to Hanford.

Day 9-12. Transit of shipment from ARECO and arrival at Hanford.

Day 13-18. Unloading, storage of capsules, and preparation of empty package for shipment at the WESF facility at Hanford.

Day 19. Departure of vehicle with empty packaging from Hanford to ARECO. The packaging and associated equipment will be surveyed prior to departure in accordance with WHC standard operating procedures.

Day 19-22. Transit of empty package shipment from Hanford and arrival at ARECO. 
WHC-MK-0523, NEV.O

CESIUM TRANSPORTATION PLAN Rev. 0 June 1996

\subsection{ADVANCE INFORMATION/TRACKING OF SHIPMENT}

RL will provide 30-day written notification to the governors of participating states (or their designees) and designated tribal officials of the schedule for initiation of the shipping campaign from ARECO. Copies of this communication will be provided to the affected State Representative Associations (SRA) and/or designated state contacts.

TRANSCOM, by procedure, provides seven-day notification electronically on shipment schedules. Use of TRANSCOM for advance information of projected shipment schedules will be coordinated by WHC. It is noted that not all corridor states have TRANSCOM nor received either training or support equipment to effectively operate this system. Where a state does not have access to TRANSCOM, a phone call by the TCC shall be made for the seven-day notification to that state/tribal designated contact. In addition, all corridor states will receive telephone notification four hours prior to shipment dispatch from the ARECO Facility (by WHC) to their designated state Cs contact.

In addition, the TCC will call the state- or tribal-designated TRANSCOM point of contact approximately two hours before the shipment is expected to enter their jurisdiction.

State and tribal representatives tracking shipments through TRANSCOM wil 1 be able to view: (1) the bill of lading; (2) DOT Emergency Response Guidebook information; (3) the shipment's route; (4) points of contact for information; (5) message traffic; and (6) shipment movement on U.S., state, and county maps.

WHC will use telephone and TRANSCOM to notify users of the shipment schedule and associated schedule changes, if any. If any abnormality occurs, the state-designated point-of-contact will provide notification through the TCC.

The TSMT driver, through the TSMT dispatch center, will provide notification to states and tribes through TRANSCOM of any unscheduled vehicle stops en route, including stops for inclement weather. Any deviation from the preferred route will comply with applicable regulations, state, tribal, and local direction, and TSMT operating procedures.

TRANSCOM backup will be provided by cellular or roadside phones as specified by procedure in the TRANSCOM Vehicle Operator's Manual and Shipper and Receiver User's Manual.

\subsection{EMERGENCY CONSIDERATIONS}

States and tribes having jurisdiction over areas through which these shipments wilT pass have primary responsibility for protecting the public and the environment, and for establishing incident command should there be an emergency involving the shipments. DOE can provide technical advice and assistance to civil authorities and carriers of DOE cargoes, when requested. 
TSMT, as the selected carrier for these shipments, is responsible for providing emergency response assistance and recovery/restoration actions, if required.

\subsubsection{Emergency Preparedness}

DOE has agreed to escort both ARECO shipments for the entire route from the ARECO Lynchburg, Virginia, facility to Hanford, Washington.

As agent for the shipper of record, WHC will provide shipper-related emergency information and maintain a 24-hour emergency telephone contact (509) 373-3800 and paging system. This number will allow for technical advice and detailed information to be available regarding the shipments within 15 minutes of receiving the first call.

States and tribes through whose jurisdictions these shipments will pass may, if desired, designate safe-parking areas to be used by TSMT drivers during adverse driving or road conditions, or during any other situation requiring an unscheduled delay. In the absence of such state or tribal designated safe-parking areas, TSMT will seek assistance from designated state/tribal authority for determining locations to use and/or avoid when selecting safe-parking areas.

\subsubsection{Notifications}

In the event of a highway incident where the shipping package is involved, the driver will notify the 911 ine, the appropriate law enforcement authority and TRANSCOM of the event. If the driver is unable to respond, TCC will inform the appropriate law enforcement authority that the driver is not responding. The authority can then locate the truck and establish incident command, if necessary.

If DOE is called upon to supply assistance in the event of an incident, the actions of its Radiological Assistance Program (RAP) will be in accordance with DOE Order 5530.3 requirements. Deployment of any DOE technical assistance or package recovery capabilities not directly associated with the RAP will be reported to the DOE-HQ Operations Center by DOE-Oak Ridge, Tennessee (DOE-TN), DOE-Chicago (DOE-CH), DOE-Idaho (DOE-ID) or RL within 15 minutes of departure of such resources from home offices.

\subsubsection{Emergency Response}

The following are emergency-related roles and responsibilities that support this plan:

- TSMT Driver: The TSMT driver, if able, will make emergency notifications and undertake first aid actions, initial incident scene control, provide assistance to first responders, and other emergency actions as described in the TSMT Contingency Plan (see Appendix B). 


\section{WHC. ME-0523, KEV.L \\ CESIUM TRANSPORTATION PLAN Rev. 0 June 1996}

- First Responders: Law enforcement, firefighting, and emergency medical service personnel will be guided in their approach to the incident scene and initial response actions by information contained in Guide 164 of the 1996 North American Emergency Response Guidebook (NAERG96) (D0T 1996), which applies to materials comprising of these Cs shipments, or by available emergency response information accompanying the shipping papers and normally available to responclers in the vehicle or accessible via TRANSCOM. Initial response to other hazards that could be involved in the accident should be guided by ERG or other appropriate protective measures and response guidelines that apply. In all cases, the incident commander for response to the CS shipments will be a local, state, or tribal authority. If states and local responders have additional procedures that provide more specific guidance, then responders will follow those procedures.

- TSMT Emergency Response Assistance: TSMT, as the carrier, will provide technical response assistance to state, tribal, and local responders as required by event scene conditions (see Appendix $B$ of this document).

- State-Level Hazardous Materials or Radiological Response Teams: States maintain specialized state-level hazardous materials and/or radiological response teams that may be activated to provide technical assistance and mitigation during emergencies. State teams are activated by the incident commander or other appropriate state or local authority.

- DOE Radiological Response Assistance: DOE's RAP is administered through eight DOE regions. RAP Region 2, administered by DOE-TN, includes the states of Virginia, West Virginia, Kentucky. RAP Region 5, administered by DOE-CH, includes Indiana, Illinois, Iowa, and Nebraska. RAP Region 6, administered by DOE-ID, includes the states of Wyoming, Utah, and Idaho. RAP Region 8, administered by RL, includes the states of Washington and Oregon and the tribal lands of the Confederated Tribes of the Umatilla Indian Reservation. The regions have radiological monitoring and assessment capabilities to provide assistance in radiological emergencies.

Additional DOE technical experts (escort team) (Section 3.1.3) are available to provide advice on characteristics of the materials and their mitigation; the package and its tiedowns; and radiological monitoring and assessment requirements for severe emergencies (if requested).

\subsubsection{Recovery}

TSMT has primary responsibility for package and transporter recovery operations. Recovery will not begin unti the emergency phase of any accident is terminated, following a decision that no radiological or other hazard is present. DOE will assist TSMT and its emergency response contractor in recovery operations, where appropriate. Specific procedures for recovery of the BUSS cask are found in Appendix B of this document. Corridor states may exercise their vehicle inspection responsibility before permitting the recovery vehicle to continue to a DOE facility or to the Hanford Site. 


\subsubsection{Cleanup and Site Restoration}

TSMT has primary responsibility for cleanup and site restoration fallowing an emergency. Standards for such actions will be as established by regulation and by authorities in the affected jurisdiction(s).

\subsection{ABOVE-REGULATORY ACTIVITIES FOR SAFE ROUTINE TRANSPORT}

No shipments will be en route during the following national holidays: New Year's Day, Martin Luther King Day, President's Day, Memorial Day, Independence Day, Labor Day, Columbus Day, Veterans Day, Thanksgiving, and Christmas Day. This would include holidays that are part of a three- or fourday holiday which includes a weekend (e.g., Independence Day).

No transport vehicle will be dispatched from ARECO during adverse weather conditions in the immediate metropolitan area (i.e., snow, ice) that could increase transportation risk. This should not be an issue since the shipments from the ARECO facility are to be performed during May through September (summer season). Peak traffic hours in the ARECO vicinity will be evaluated by the Virginia-designated authority. This information will allow for coordination between ARECO, WHC Transportation and Packaging, and the carrier to limit exposure of the shipment to the surrounding motor traffic at time of dispatch from the ARECO facility.

DOE, WHC, and TSMT recognize the states concerns and their policies regarding weather/road conditions and safe-parking procedures. Currently, DOE/WHC has enacted that there be one season related to the dispatch of the vehicle from ARECO: Summer Season.

Summer Season, May 1 - September 30:

- Advance weather and driving condition checks will be made by the TCC staff using WSI Weather for Windows Service. It is the states' responsibility to notify the TCC if weather or road conditions are expected to be unacceptable during the projected shipment period. NOTE: For this transportation plan, Bad Weather Policy (Winter Season) is not part of this plan since ARECO Cs transport is only scheduled to occur in the Summer Season. If such transport does not occur during the Summer Season window, this plan will be amended to include Winter Season Bad Weather Policy agreements for the entire transport corridor prior to transport occurring between october 1 - Apri 30.

Advance weather information will be provided to TSMT via TRANSCOM. The driver(s) will use this information in planning travel distances and determining potential safe-parking locations while in transit (if required). If, during shipment, weather/road conditions warrant, the drivers will park the vehicle at a state-designated safe-parking area or at the first available safe-parking area as weather conditions dictate. In the absence of state/tribal safe parking protocol, TSMT will seek assistance from the designated state/tribal authority as described in Section 3.4 of this document. The vehicle will remain at the agreed-to location until the designated authority, TSMT, and escort personnel agree conditions will allow safe transport to continue. 


\section{WHe - MR-0523, ttVO \\ CESIUM TRANSPORTATION PLAN. Rev. 0 June 1996}

It is recommended that weather/road conditions are evaluated between the designated authority, TSMT (drivers), and escort personnel and that all parties agree the vehicle is not being dispatched too quickly into conveyance once conditions improve.

\section{6 INFORMATION ASSISTANCE CONSIDERATIONS}

DOE-HQ has prepared a packet that provides specific information about the capsule return program. Included in the packet are photographs and cut-away views of the capsules themselves as well as diagrams and specifications of the packaging that will be used. Information sheets about handling and loading procedures, the carrier (TSMT), the general recall campaign and the shipments' points of origin and destination are included. A fact sheet containing general information also is included. These packets have been provided to corridor states and tribes, and additional sets wiTl be provided by DOE as requested.

State and tribal authorities are contact points for information requests within their jurisdictions. DOE is working with states and tribes to coordinate information requests and has identified points of contact at RL and DOE-HQ to respond to requests for information from the public and the media.

The ARECO facility, as the point of origin for these shipments, has special public information and communications considerations. DOE can assist ARECO, if requested, to help coordinate information products (such as the information packets) and public involvement activities as appropriate. DOE, WHC, and affected agencies described in this transportation plan will prepare a communications strategy to coordinate public information along the shipping carridor.

\subsection{PACKAGING DESCRIPTION}

The packaging for transporting the capsules from ARECO is designed to provide confinement of its contents as required in 10 CFR 71 . The packaging is composed of stainless steel shielding and is licensed by the NRC and DOE as a Type 8 SF packaging. The gross weight of each loaded package being shipped from ARECO could be $15,286 \mathrm{~kg}(33,700 \mathrm{lb})$ and could contain a maximum of $750,000 \mathrm{Ci}$ of $\mathrm{CS}$ chloride. Loading activities will meet the requirements of the current packaging's SARP and $C O C$ as approved by NRC and/or DOE.

\subsection{REFERENCES}

10 CFR 71, "Packaging of Radioactive Material for Transport, " Code of Federal Regulations, as amended.

10 CFR 73, "Physical Protection of Plants and Materials, " Code of Federal Regulations, as amended. 


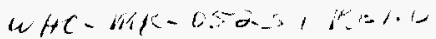

CESIUM TRAISPOR ATIIN PIAHI Rev. 0 JunE 1996

49 CFR, "Hazardous Materials Regulations:" Code of Federal Regulations, as amended.

DOE Order 460.1, Packaging and Transportation Safety Requirements, U.S. Department of Energy, Washington, D.C.

DOE Order 5530.3, Radiological Assistance Program, U.S. Department of Energy, Washington, D.C.

DOT, 1996, North American Emergency Response Guidebook (NAERG96), U.S. Department of Transportation, Washington, D.C.

DOE/NRC Beneficial Uses Shipping System (BUSS) Cask Certificate of Compliance, USA $/ 9511 / B(U)$, U.S. Department of Energy and U.S. Nuclear Regulatory Commission, Washington, D.C.

TRANSCOM Operational Procedures and User's Guide, TCOM-OPSP, current revision.

SAND83-0698, TTC-0430, Beneficial Uses Shipping System (BUSS) Cask Safety Analysis Report for Packaging, Sandia National Laboratory, Albuquerque, New Mexico.

In addition to the preceding regulations covering transportation of hazardous materials, there are several transportation acts and regulations which assign responsibilities, establish requirements, and prescribe procedures for transportation in general or in other specific areas. Some of these important references are:

1. Hazardous Materials Transportation Act. 49 U.S.C. 1801 et seq. defines regulatory and enforcement authority of the Secretary of Transportation to protect the nation against the risk inherent in the transportation of hazardous materials. 
WHE - VIK-0S23, KEV O

CESIUM TRANSPORTATION PLAN REv. 0 June 1996

APPENDIX A: TSMT HAZARDOUS WASTE AND RADIOACTIVE

MATERIALS DRIVER'S TRAINING 


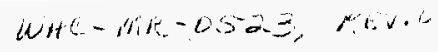

CESIUM TRANSPORTATION PLAN REV. O June 1996

\section{DRIVER'S TRAINING}

The training program consists of the complete operation and functions of our company. Our program consists of the driver's function and management functions of our company. It also acquaints the student with and updates all state and federal laws, rules, and regulations pertaining to the transportation industry. These consist of dimensional requirements, whether state or federal; regulations pertaining to the transportation of hazardous materials; legal requirements for the preparation of freight bills; freight claims and prevention, accident prevention and reporting, personal injury and prevention; DOT regulations, including inspections and requirements of motor vehicles; logs and hours of service; other branches of government involved in the transportation field, such as the Environmenta? Protection Agency, OSHA, and DOE, and their regulations covering movement of hazardous materials. The program also consists of hands-on tieing, securing, and tarping of open equipment and the movement of this type of freight.

We have devised our own program on videotape. Everything on the tape is based on written literature which is issued to each driver as reference material while in the class and to refer to once the driver is put to work. During the instruction class, the driver is given a practical problem and questionnaires to review subjects that are covered. These are: Department of Transportation Questionnaire for Review of the Federal Motor Carrier Safety Regulations Book; a Hazardous Materials Test covering Hazardous Material Regulations, and Requirements; a sample problem covering preparation of a Company Bill of Lading, completing a drivers' Daily Log Sheet, recording a movement and a pay report.

After going to work, drivers are monitored closely by their assigned Fleet Manager, and if found Tax in any of these subjects, are returned to class to review the subject. In many cases, this is done on a one-on-one basis, or the driver will attend a class with a group covering this subject.

Tri-State meets or exceeds the training requirements as outlined in 49 CFR Subpart "H" 172.700 . Copies of our Hazardous Waste and Radioactive Driver's Training are attached. 
WHC- HIR-OS 23, HEV.C

CESIUM TRAISPORTATION PLAN REV. 0 June 1996

\section{EMPLOYEE TRAINING RECORD SUBJECT}

Introduction to Regulations - CFR 10, 29, 40,49

Image and Professionalism (Signed Affidavit)

Vehicle Inspection Requirements

Waste Characteristics and Classifications

Material Safety Data Sheet

Hazard Communication and Right to Know

Film-A No Nonsense Look at Substance Abuse (as required)

DOT Regulations Covering:

- Uniform Hazardous Waste manifest and/or Shipping Papers

- Marking Requirements

- Labeling and Placarding Requirements

- Route Restrictions

- Package Quality (Spec and non-Spec)

- Proper Container Inspection

- Blocking, Bracing, and Cargo Tiedown (van and flatbed)

- Proper use of Protective Equipment

- Respirator Fit Test

- Drum-Overpack

- Emergency Contingency PIan and Spill Containment

- Emergency Response Guide Book

- Proper use of a Fire Extinguisher and Film

- Review F.M.C.S. 397

- Introduction to Radioactive Transport and Film (see Curriculum)

- Workshops (Manifest and Placarding and Compatibility Exercises)

- Seasonal Safety Film-Various Driving Conditions

- Overall Safety Rules - Test - Review and Certifications (see Curriculum)

Date:__ Hours:___ HazMat Instructor:

Date:__ Hours:______nnual Review:____ Instructor:

Date:__ Hours:____ First Aid \& Adult CPR Instructor:

Date:_Hours:_______nnual Recertification CPR Instructor:

Date:__ Hours:________t'I Safety Counci 1,PID-DDC INSTRUCTOR:

Date:__ Hours:____ Spent Fuel \& Hwy Route Control (HRCQ) INS.

Total Training Hours ( ) ( ) ( ) ( )

\section{Employee Signature}

The above-named person has satisfied the training requirements pursuant to 49 Subpart "H", 172.700 . 
WHC- MH -OS ב Z, EV.C

CESIUM TRANSPORTATION PIAV REV. 0 June 1996

\section{HAZARDO JS MATERIALS D?IVER TRAINING CURRICULUM}

1. INTRODUCTION AND HOUSEKEEPING RULES

2. INTRODUCTION TO REGULATIONS AND PROCEDURES

A. CFR 10 (Radioactive)

B. CFR 29 (OSHA) (right-to-know)

C. CFR 40 (EPA)

D. CFR 49 (Transportation)

E. Customer Relations

F. Procedure-Nuclear Facilities

1. Inspection

2. Declaration of Contraband

3. CHARACTERISTICS AND CLASSIFICATIONS

A. Hazardous Classes

1. Materials (Virgin Product)

2. Substance (EPA Designate)

3. Waste (by-product)

4. ORM (Other Regulated Material) (diagram)

5. NOS (not otherwise specified) - Further Description Required

4. DOT REGULATIONS PERTAINING TO

A. Container Markings (Cross Reference to Manifest)

B. Product Identifications

C. Labeling

D. Placarding-Prepare Examples-Several-also Workshop Material

E. Bulk Placarding

F. Shipping Papers (containing Hazardous Materials)

G. Compatibility (page 2l6 Tri-state manual)

H. Uniform Hazardous Waste Manifest

1. Waste Manifest-that of State Receiving Product (Facility)

2. Various State Manifest Requirements (PCB-Specific)

WORKSHOP - Have Drivers Prepare Several Manifests and Complete Several

Placarding Exercises

5. PACKAGE QUALITY

A. Types of packages (most commonly transported by TSMT)

1. Drums (Types)

a. Steel $55 \mathrm{Gal}$ Drum, and Open Top w/ Band

b. Plastic 59 Gal

c. 5 gal Steel and Plastic

2. Bags (Transport of STudge or similar Substances)

B. Spec and Non-Spec

1. How to Identify (Location)

2. Info Needed When Discussing Packaging with Safety Dept

C. Inspection of Container

1. We Have the Right to be Present to

a. Be Sure Containers are of Proper Quality

b. Check for any Type Damage (Crease, Dent, Puncture, and Tightened)

c. Check for Proper Identification (Compare w/ Manifest) 


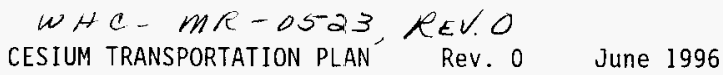

d. Proper Labeling - Markings

e. Compatibility

f. Proper Loading (per Driver Instructions)

g. Discuss Weak Areas of Drums

D. Blocking, Bracing, and Cargo Tiedown

1. Utilization of Pallets to Fill Cavities

a. Especially when Spreading a Load

b. Securements of Drums to Flatbeds

c. Floor Plan (LTL) - Helps w/ Placarding

6. Leaks and Spills

A. Personal Protective Equipment (see Checklist)

B. Proper Storage, Use, Fit, and Test Procedure for Respirator

C. Spill Kit, Contents, and Use

D. Spill Containment (Discuss Several Situations)

E. Drum Overpack (Demonstration)

F. Procedure to Pump Fluids (Aimed at PCB Transporters)

G. Emergency Response Guide Book (ERG could appear on Manifest in Several Areas or a Copy w/ Paperwork) - Impress Keep w/ Paperwork also Material Safety Data Sheet

H. Emergency Contingency PTan

I. Exercise in Proper Use of "Drivers Pocket Guide to Hazardous Materials" (also Used when Working and Discussing Manifest in the Workshop)

J. Know and Understand Emergency Response Guide Book (Usage and Carriage)

7. Proper Use of Fire Extinguishers

A. Types of Extinguishers Used Depending on the Type of Fire A, B, C,

B. $\quad F i 1 m$

C. Proper Inspection and Procedure for Keeping TSMT Fire Extinguishers in a Ready State of Operation

8. Professionalism

A. Secured Transport Requirements (see Handout)

B. Person

C. Beards

D. Animal

E. Discuss Tri-State Motor Transit Attire

F. Contraband (Examples and Declaration)

9. State Certification

A. Various State Requirements

10. Discuss - HM-181 AND HM-126F.

(as Changes Occur Material to be Modified)

11. Instructor to show A.T.A. Film, Between each Segment will go over Test

Questions, A.T.A. Workbook, Expound Where and When Needed

12. Introduction to Radioactive Materials Transportation

A. See Attached Curriculum 
WHAC-MK-0.S2 3, KEV.C

CESIUM TRANSPORTATION PI_AN ReV. 0 June 1996

13. Administer Formal Respirator Fit Test

14. Administer Test

A. Review Test Results with Driver

15. Prepare and Distribute all Driver Certifications and State Applications DAYS 1,2, AND 3

\section{DAY 4}

1. Standard First Aid and Adult CPR

A. Review Film by Segments

B. Administer Skills Test and Written Test

C. Certification Paperwork

Tri-State Transports all Facets of the Nuclear Fuel Cycle

Introduction to Radioactive Materials Transportation, Based on Tri-State's Transportation Manual

1. Introduction to Regulations

A. CFR 10 (Radioactive)

B. CFR 29 (OSHA) (Right-to-know)

C. CFR 40 (EPA)

D. CFR 49 (Transportation)

E. Customer Relations

F. Procedure-Nuclear Facilities

a. Inspection

b. Declaration of Contraband

2. What is Radiation? (the Decaying Process of Unstable Material by Giving off Alpha, Beta, Gamma, Neutrons, and X-ray)

A. There are two types of Radiations

1. Non-Ionizing (i.e., light, Radar Range, Radio and TV Waves (Frequencies)

2. Ionizing Energy

3. Definitions and Terms

CPM - Counts per Minute

DPM - Disintegrations per Minute (Smear Test)

(Different Way of Detecting Rate of Decay) (Energy and Particles)

"How Many Atoms are Decayirig"

Curie - 37 Billion Disintegrations per Second

Contamination - Material on a Surface (Surface Contaminated) (Contact)

Exposure - Radiation from "RAM" (Energy and/or Particles)

(No Contact)

Atom - Basic Building Block of All 
WHC-MK-OS25, KEV. O
CESIUM TRANSPORTATION PLAN ReV. 0 June 1996

A. Solids, Liquids, or Gases

(Configuration Determines the A. Above)

Millirem $(\mathrm{mr} / \mathrm{hr})$ : Measures the Intensity of

the Energy being Released.

(Rheostat - Light-

Lightmeter)

Enriched Material: One or More Isotopes of a

Constituent (Material) has

been Increased

Dose: Quantity of Radiation (Total)

Dose Rate: Quantity of Radiation or Energy

Received in a Period of Time

Isotope: Various Species of the same Element

(i.e., Uranium - 233-234-235).

Fission: Splitting of a Heavy Atom (Large) such as

Uranium (Atomic Material) (Need Fissile Material

for this to the Place (i.e., Uranium Plutonium)

A. Nucleus-Center Part of the Atom-
Neutron/Proton Make up the Nucleus
Circle (Electrons Eircle the Nucleus)

4. Energy Production Process (Reactor)

A. A Controlled Chain Reaction is a self-sustaining series of nuclear fissions taking place in a reactor core. Neutrons produced in one fission cause the next fission.

B. For every occurring reaction, you produce one or more reaction. This is called a controlled chain reaction (nuclear reactor process).

5. Fissile I, II, III, (rate of interaction determines the rating; (energy being produced).

A. The degree of control required (T.I.-50) for both transport and storage (not to exceed a T.I. of 10 per package (criticality control) (incident) (exception exclusive use). (A reading at $3.3^{\prime}$ determines the T.I. placed on the label).

6. During the decaying process, the following types of energy are given off:

a. Alpha - largest particle (paper shield) (inches) (cannot penetrate clothing or outer layer of skin). 
B. Beta - small particle (sheet metal-wood) (few feet) (has short range).

C. Gamma - energy (pulsating) also known as photons (heavy penetrating power) (lead-concrete-water, several inches or feet) (travels by air several feet).

D. Neutron - particle smaller than an alpha particle (caused by the reaction within the atom and the capturing of another particle) (shielding, hydrogen, water, or concrete).

7. What is and where do you find radon gas?

Given off during the natural decaying process of uranium within the ground.

8. Natural radioactive materials do not necessarily emit high levels of radiation.

9. Enrichment process:

The radioactive materials are first mined, then go through a chemical process, recovered in the form of a powder (yellow cake), then converted to UF6, (used to isolate uranium 235) then to uranium dioxide (solid form), then formed into pellets assembled into fuel assemblies and shipped to the reactor site.

10. Placarding requirements

A. Empty - if contains less than $0.5 \mathrm{M} / \mathrm{R}$ external radiation

B. LSA - radioactive (stenciled on container) (unless exclusive use)

C. UF6 - radioactive and corrosive (1,000 $\mathrm{p}$ or more)

D. Yellow III - radioactive

E. HRCQ - radioactive (special)

11. Shipping Papers

A. Basic format (see example)

1. Required items on your shipping papers (see example)

2. Other attached paperwork required when shipping RAM

12. Usage of survey instrument (allowable readings)

a. Internal (exclusive use) (1000-200-10-2)

b. 0ther - 200-10-2

13. Altowable annual exposure 

A. 5 rem per year - accumulative (radioactive workers only) ( 1 rem equals 1,000 millirem)
b. Tri-State Motor Transit Co. - Drivers (500 millirem per year) (accumulative)

14. Dosimeter - types (detects released radiation)
a. Visual
b. Film
c. Audio

15. Tiedown responsibility

A. Shipper may assist or perform on some casks - however still carrier responsibility.

16. What is yellow cake?

A. Uranium concentrate

17. Highway route control: when?

A. Energy within a single container that exceeds 3,000 times $a_{1}$ or $a_{2}$ value - or 30,000 curies, whichever is least (or any spent fuel).

18. SFRM - special form RAM - encapsulated (sealed material), (not radiation) if opened, you must destroy the packaging.

19. SNM - special nuclear material - plutonium, uranium (enriched) isotope $233-235$.

20. Parking

A. Normal occurrence parking areas

1. Not at
A. Movie houses
B. Grocery stores
C. Malls
D. Small motels (unless truck parking allowed)

B. Truck stops and safe havens, never next to another RAM load, or explosives (especially when running convoy-fuet).

21. Trailers

A. Never unhook from a trailer unless you obtain authorization from Tri-State supervisor

B. Never leave unattended for long periods of time 
C. If empty or urloaded cask you must have

1. Company authorization

2. Locations management authorization, name phone number of location and a $w / c$ number for driver contact

3. If labeled do not drop trailer

22. Film on transport and storage of spent fuel

A. Test crash 


$$
\begin{aligned}
& \text { WHC- MR-0.523, KEV.O } \\
& \text { CESIUM TRANSPORTATION PLAN ReV. } 0 \text { June } 1996
\end{aligned}
$$

\section{DRIVER/ESCORT TRAINING SYLLABUS}

SYNOPSIS: The following is a syllabus for a ten-hour course of instruction for personnel in the motor transportation industry who will be hauling loads of irradiated (spent) nuclear fuels and other highway route controlled quantity radioactive materials shipments. The course will be offered at Tri-State Motor Transit Co.

0730 to 0745

\section{Wel come}

\section{Introduction to Course}

Registration, introductions and introductory remarks. Suggestions for note taking and an overview of topics to be presented. An important component will be the motivating of students to the need for strict attention and high level of performance during and after the course.

0745 to 0830

0830 to 0845

0845 to 1000

\section{Review of Regulations}

Overview of regulations, including DOT, NRC, DOE, and State as they apply to the subject matter.

\section{BREAK}

\section{Radiological Considerations}

A review of the nuclear fuel cycle and an overview of the functions of a nuclear reactor. Discuss the radiological change a nuclear fuel assembly undergoes during the fission process, and its hazardous characteristics after irradiation.

Review the general structural characteristics of a fuel shipping cask, discussing the manner in which it is loaded, decontaminated and handled during all phases of the shipping cycle.

Review the definition of highway route controlled quantity and discuss the radionuclides and the chemical and physical form of the material most likely to be shipped as highway route controlled quantity. Discuss the hazards of each radionuclide and each form.

Review the use and capability of the radiation detection device carried on board the transport vehicle. Review the emergency procedures to be followed in the event of suspected or confirmed radioactive leakage resulting from an accident or any other cause. 


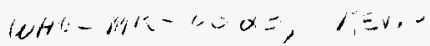

CESIUM TEANSPORTATION PI.AN Rev. 0 June 1996

1000 to

1015

Driver Compensation

A review of how drivers assigned to HRCQ and Spent Nuclear Fue] Shipments are paid. Instruations on how drivers should complete their payroll documents to improve proper processing in payroll.

1015 to

1030

Reporting of Accidents \& Interacting with Law Enforcement and other Regulatory Personnel

A review of accident reporting procedures and the importance of professionatism in interacting with law enforcement and regulatory agencies.

1030 to

1100

\section{Protection of Safeguards Information}

Review of NRC regulations and NUREG-0794. Discussion of what constitutes "Safeguards Information" and methods of protecting such information. The operations of the on-board radio, telephone and satellite systems will be discussed with emphasis on the prudent utilization of this equipment for communications.

1100 to

1130

\section{Vehicle Immobilization Device Operation}

A review of the immobilization device and how its functions relate to routine and emergency type operations of the vehicle. Discussion of when, why, and how to use special equipment to immobilize the tractor.

1130 to 1200

\section{Route Planning, Selection and Deviation}

Review of the criteria utilized in developing a route, the NRC functions of route approval and providing route overviews. A review of a typical route overview and the information contained therein with emphasis on the necessity to follow these routes and utilize the listed stops to the fullest extent practical.

1200 to

Lunch (catered)

1300 to 1345

\section{Spent Fuel Operating Procedures}

An overview of the written procedures which provide detailed methods to be utilized by TSMT in providing for the safe, secure transport of spent fuel. 
1345 to

1400

1400 to

1415

1415 to

1500

1500 to

1515

1515 to

1530

1530 to

1615

1615 to

1730
Vehicle Maintenance and Inspections

A review of past experience with vehicle inspections. Emphasis on the need for high standards of maintenance and inspection.

\section{Comments from Dispatch}

Discussion on how drivers interface with Dispatch on these special assignments, including a review of the documentation involved.

\section{General Review of Material Covered Informal Question \& Answer Period}

A general review of material presented with emphasis on information pertinent to regulatory compliance and safe operations.

Informal discussion period for any who may have questions relating to the subject matter.

\section{BREAK}

Film-Spent Fuel Transportation, Various Testing Methods

This film reflects some of the engineering and testing that goes into developing casks for transporting spent nuclear fuel.

\section{Written Examination}

Review, Evaluation, \& Certification

The graded written test will be discussed with the class along with the results of other evaluations done during the course.

Certificates will be issued to all drivers who have satisfactorily completed this course. 
wite-

CESIUM TF:ANSPORTATION PIAV Rev. 0 June 1996

This page intentionally left blank. 
$\begin{array}{lrl}\text { WHC - MR-OSQ3 } & \text { KEV.O } \\ \text { CESIUM TRANSPORTATION PLAN } & \text { ReV. } 0 \quad \text { June } 1996\end{array}$

APPENDIX B: TSMT/OHM EMERGENCY RESPONSE/CONTINGENCY PLAN AND CS CASK RECOVERY GUIDE 
WHC-MR-OS23, KEV.C

CESIUM TRANSPORTATION PLAN Rev. 0 June 1996

TABLE OF CONTENTS

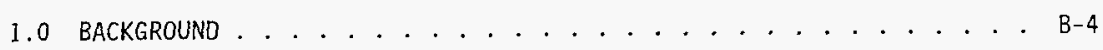

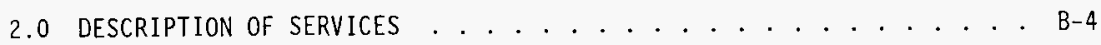

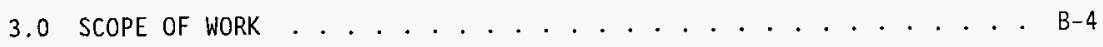

4.0 APPLICABILITY ..................... . . . . . .

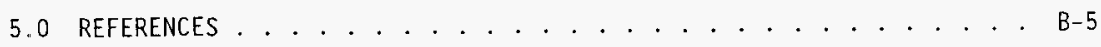

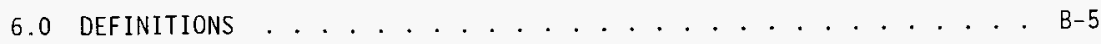

7.0 REQUIREMENTS . . . . . . . . . . . . . . . . B-6

7.1 TOOLS, MATERIALS, EQUIPMENT . . . . . . . B-6

7.2 MAINTENANCE - EMERGENCY RESPONSE KIT . . . . . . . . . B-6

7.3 EMERGENCY RESPONSE CAPABILITIES . . . . . . . . . . B-7

8.0 RESPONSIBILITIES . . . . . . . . . . . . . . . . . B-7

8.1 OHM PROJECT MANAGER OR DESIGAEEE . . . . . . . . . . . B-7

8.2 ANDERBERG COMMUNICATIONS . . . . . . . . . . . . . . . . B-7

8.3 EMERGENCY RESPONSE KIT MAINTENANCE . . . . . . . . . . . . B-7

8.4 EMERGENCY RESPONSE TEAM ORGANIZATION ........... B-8

8.5 SKILLED SUPPORT PERSONNEL ..................... . . . . . .

9.0 TRAINING . . . . . . . . . . . . . . . . . . . . . . .

9.1 TEAM MEMBER PREREQUISITE qUALIFICATIONS . . . . . . . . . B-9

9.1 .1 Team Leader . . . . . . . . . . . . . . B-9

9.1 .2 The Team ................... B-9

10.0 NOTIFICATION . . . . . . . . . . . . . . . . . B-10

10.1 REQUEST FOR RESPONSE $\ldots \ldots \ldots$.

10.2 EMERGENCY RESPONSE TEAM . . . . . . . . . . . . . . . . B-10

10.3 NON-OHM SUPPORT . . . . . . . . . . . . . . . B-11

10.4 STATE AND FEDERAL AGENCIES ................. B-11

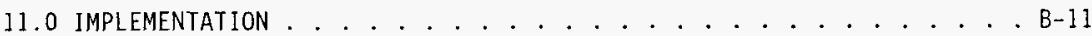

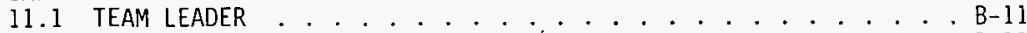

11.1 .1 Instructions .................. . . . . .

11.2 TEAM LEADER ACTIONS ................. . . . . . . . . . . .

12.0 COORDINATION WITHIN THE LOCAL INCIDENT COMMAND SYSTEM . . . . . . B-12

12.1 STAGING . . . . . . . . . . . . . B-12

12.2 INCIDENT COMMAND $\ldots \ldots \ldots$. . . . . . . . . . . . . . . . . .

12.3 COMMUNICATION . . . . . . . . . . . . . . . . . B-13

12.4 ESTABLISHING THE INTERACTION WITH THE ICS . . . . . . . B-14

13.0 RESPONSE ACTIONS WITHIN THE LOCAL INCIDENT COMMAND SYSTEM . . . . . B-14

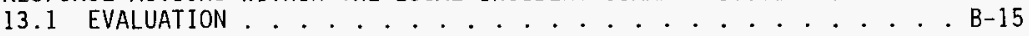




\section{WHe, MR - OSA3, REV.O \\ CESIUM TRANSPORTATION PLAN ReV. 0 June 1996}

\section{TABLE OF CONTENTS (Continued)}

13.2 SITE ENTRY . . . . . . . . . . . . . . . . B-15

13.2.1 Survey and Reconnaissance . . . . . . . . . . . . B-16

13.2.2 Priority for Initial Entry Monitoring . . . . . . . . B-17

13.2.3 Periodic Monitoring .............. . . . B-17

13.2.4 Ambient Atmospheric Concentrations . . . . . . . . B-18

13.2.5 Levels of Protection .............. . B-18

13.3 ENTRY TEAM REQUIREMENTS .................... . . B-18

13.3.1 Dress-Out Instructions . . . . . . . . . . . . . . B-19

13.3.2 Communications Check Between Personnel . . . . . . B-19

13.3.3 Communication Check Points . . . . . . . . . . B-19

13.4 WORK ZONES . . . . . . . . . . . . . . . . . . . . . . . . B-19

13.4.1 Zone 1: Exclusion Zone ........... . . B-19

13.4.2 Zone 2: Contamination Reduction Zone . . . . . . . B-20

13.4.3 Zone 3: Support Zone. . . . . . . . . . . . . . . B-20

13.4.4 0ther Consideration for Work Zones . . . . . . . . . . B-2l

13.5 PROTECTIVE ACTION . . . . . . . . . . . . . . B-22

14.0 DECONTAMINATION . . . . . . . . . . . . . . . . . . . . . . B-22

14.1 CONTAMINATION REDUCTION CORRIDOR . . . . . . . . . . . . B-23

15.0 RECORDS AND REPORTS . . . . . . . . . . . . . . . . B-23

15.1 FOLLOW-UP . . . . . . . . . . . . . . . . B-23

16.0 EMERGENCY INSTRUCTION TO TSMT DRIVERS . . . . . . . . . . . . . . . B-24

17.0 TSMT EMERGENCY RESPONSE ORGANIZATION . . . . . . . . . . . . . B-26

18.0 OHM EMERGENCY RESPONSE ORGANIZATION . . . . . . . . . . . . . . . B-26

19.0 CS CASK RECOVERY GUIDE . . . . . . . . . . . . . . . . . . B-27

19.1 INTRODUCTION . . . . . . . . . . . . . . . B-27

19.2 SCOPE . . . . . . . . . . . . . . . . . . . . . B-27

19.3 INSPECTION AND RECOVERY PROCEDURES . . . . . . . . . . . . . B-28

ATTACHMENT A: EMERGENCY RESPONSE KIT INVENTORIES AND INSPECTION

CHECK SHEET . . . . . . . . . . . . . . . . . . . . B-35

ATTACHMENT B: ANDERBERG COMMUNICATIONS EMERGENCY NOTIFICATION

CHECK SHEET . . . . . . . . . . . . . . . . . B-37

ATTACHMENT C: QUALIFIED VENDORS LIST . . . . . . . . . . . . . . . . B-39

ATTACHMENT D: QUALIFIED CRANE AND LIFTING RESOURCES . . . . . . . . . . B-45

\section{LIST OF FIGURES}

1 Diagram of Site Work Zones . . . . . . . . . . . . . . . . B-22 
WHC-MK-0S23, REV.C

CESIUM TRANSPORTATION PLAN Rev. 0 June 1996

\section{CONTINGENCY PLAN FOR INCIDENTS INVOLVING TRANSPORTATION OF CS CAPSULES}

Should Tri-State Motor Transit Co. (TSMT) become involved in an accident/ incident while transporting DOE CS capsules from the ARECO Facility, the following contingency plan will be enacted.

\subsection{BACKGROUND}

TSMT has primary responsibility for package and transporter recovery operations. TSMT has retained OHM Remediation Services Corp. (OHM), to be the emergency response recovery contractor for these two shipments. Emergency response coverage shall be provided along the entire shipment route from Lynchburg, Virginia, to the Waste Encapsulation Storage Facility (WESF) at the Hanford Site in Washington State.

\subsection{DESCRIPTION OF SERVICES}

OHM is providing emergency response and recovery contractor services for TSMT covering the ARECO Cs capsule shipments only. The emergency response and recovery capability will consist of trained personnel and equipment on standby in Denver, CO, and Columbia, SC. In the event of an incident/accident, the OHM Emergency Response team will be responsible to perform all the actions necessary to place the shipment safely back en route to the Hanford Site, located in southeast Washington state. These actions include, but are not limited to, clearing the accident scene, obtaining safe parking for the shipment, security for the shipment during repairs, and disposition of damaged equipment. Repair or replacement of the equipment will be coordinated with the TSMT Safety and Operations Departments. These actions will be performed with approvals from TSMT, technical guidance from Westinghouse Hanford Company (WHC), the U.S. Department of Energy (DOE), and the appropriate state and local law enforcement agencies.

\subsection{SCOPE OF WORK}

The level of response will depend upon the type and severity of the incident. Qualified personnel within TSMT and OHM have been trained on this Contingency Plan. Emergency response and communications equipment has been procured and activated for these shipments. The equipment list includes: (a 24-hour 1-800 number), pagers for on-call team members, and a citizen-band (CB) radio. Equipment to stock the emergency response kits will be tested, calibrated, inventoried, packed, and sealed. All emergency response equipment has been selected specifically for the ARECO shipments (see Attachment A). A vehicle will be provided during the actual time the shipment is on the road to allow transport of equipment and personnel in case of a transportation incident.

Also included in this document is the implementation of a notification system for occurrences and a coordinated, preplanned response by OHM personnel to an incident involving the transportation of Cs capsules. 
The Emergency Response team provides the existing emergency management resources with trained personnel and equipment for radiological emergencies. The team works in cooperation with TSMT and the local jurisdiction.

Notification of incidents will be required to ensure that OHM Corporate Management and TSMT is aware of any problems and, if necessary, takes the appropriate action. The Emergency Response team is activated by a 24-hour $1-800$ service which in turn notifies the team members by pagers or direct phone.

Response to any real or potential emergency can include any action taken to minimize the consequences of the situation. The degree of response will be determined according to the magnitude of the incident.

\subsection{APPLICABILITY}

Instructions set forth in this document shall apply specifically to all OHM employees involved in the Cs capsules shipment. Emergency situations may call for individuals other than OHM employees to request the activation of the Emergency Response team.

\subsection{REFERENCES - OHM SPECIFIC COMPANY PROCEDURES*}

SF-016, "Incident Reporting Procedure" *

SF-017, "Incident Investigation Procedure" *

OSHA 29 CFR 1910.120 "Hazardous Waste Operations and Emergency Response"

TN-002, "Training Procedure" *

\subsection{DEFINITIONS}

Incident - Any unplanned event resulting in death, personal injury, exposure to a significant radiological hazard, property damage, loss of assets, fire or explosion, spill, release, adverse publicity, or regulatory compliance issue.

Call Duty - The assigned duties of an Emergency Response team requiring them to be available 24 hours a day for the period the shipment is en route to Hanford.

Caller - The individual who contacts Anderberg Communications personnel with the initial notification of an incident. The caller will likely be a WHC escort individual at or near the scene or a TSMT representative.

Emergency - An emergency or potential emergency is defined as any of the following:

- The loss or theft of radioactive material. 
WHC - MR - OS223, KEV.

CESIUM TRANSPORTATION PLAN

Rev, 0 June 1996

- An over-exposure of persons from sources of ionizing radiation or potential release of radioactive material.

- A transportation accident that involves damage or delay of the shipment.

- A potential radiological risk of sufficient magnitude to involve the following:

1) Evacuation or control of the movement of people to minimize exposure to radiation

2) Medical evaluation of individuals.

- Unplanned release of radioactive materials which requires notification to a regulatory agency.

Class A Emergency - The lowest-ranked emergency for which response is required. A release of radioactive materials and/or increase in radiation levels are not apparent.

Class B Emergency - The middle-ranked emergency in which a response is required. Increase in radiation levels are apparent.

Class C Emergency - The highest-ranked emergency in which a response is required. Radioactive materials release and/or an increase in radiation levels are apparent.

Emergency Response Kits - Kits that contain equipment and materials necessary for the Emergency Response team to respond to the majority of emergencies involving radioactive materia?. There have been two kits that have been assembled: one is located at the OHM Remediation Services, 4897 Oakland Street, Denver, CO 80239. The second response kit is assembled at OHM Remediation Services, 250 Berryhill Rd., Columbia, South Carolina 29210. Team members are able to access the buildings 24 hours a day.

Package - The container surrounding the radioactive material, e.g., the Beneficial Uses Shipping System (BUSS) Cask.

\subsection{REQUIREMENTS}

\subsection{TOOLS, MATERIALS, EQUIPMENT}

The items listed in Appendix B, Attachment A shall be assembled into kits and kept ready at all times. The kits shall be kept ready at the OHM offices located in Denver, CO, and Columbia, SC. Hereafter these tools, materials, and equipment will be referred to as the Emergency Response kits.

\subsection{MAINTENANCE - EMERGENCY RESPONSE KIT}

The maintenance of each Emergency Response kit will be the responsibility of the OHM Project Manager or his designee. The kits will be inventoried on a monthly basis (Appendix B, Attachment A). The inventory will include: checking instruments, replacing batteries if necessary, and performing a physical and operational inspection of the kit contents. 
WHC- $M E-0523$, KEV.O

CESIUM TRANSPORTATION PLAN Rev. 0 June 1996

\subsection{EMERGENCY RESPONSE CAPABILITIES}

The following OHM Facilities will have Emergency Response capabilities:

- OHM Remediation Services Corp. 4897 Oakl and Street

Denver, C0 80239

(303) $371-8252$

OHM Remediation Services Corp.

1024 Ferguson Street

Columbia, SC 29201

(803) 256-1555

\subsection{RESPONSIBILITIES}

\subsection{OHM PROJECT MANAGER OR DESIGNEE}

The OHM Project Manager shall follow this established DOE/WHC Transportation PTan and the company-specific Health and Safety Plan. The OHM Project Manager shall also establish an Emergency Response team to ensure the public safety and health in the event of an incident involving the Cs capsules.

The OHM Project Manager shall also ensure that the OHM notification system is established with affected persons, e.g., customers, vendors, carriers, and government and civil agencies.

The OHM Project Manager will have the following responsibilities:

- Prepare, review, and update the OHM Emergency Response Procedure.

- Establish the team and ensure replacement of team members that can no longer fulfill the duties.

- Ensure team members are properly trained and training is documented in accordance with TN-002, Training Procedure.

- Ensure the kits are properly inventoried and stored.

- Perform periodic tests of the Anderberg Communications notification line and the pagers.

\subsection{ANDERBERG COMMUNICATIONS (1-800-925-4959)}

Anderberg Communications personnel shall be prepared to:

- Record the caller notification of incidents, accidents, and/or emergencies on the Emergency Notification check sheet (Appendix B, Attachment $B$ ).

- Call the five pager-system numbers to alert the Emergency Response team members (Appendix B, page B-38).

- In emergency situations, stay by the telephone and make or answer telephone calls as directed by the Emergency Response team.

\subsection{EMERGENCY RESPONSE KIT MAINTENANCE}

The OHM Project Manager shall designate a responsible individual to ensure Emergency Response kit maintenance prescribed in this section. 


\section{$W H C-M R-0523, K \boxminus V . O$ \\ CESIUM TRANSPORTATION PLAN Rev. 0 June 1996}

- Maintain a list of Emergency Response kit radiation detection instruments and their calibration due dates. Package and ship the radiation detection instruments to the Calibration Facility two weeks prior to their calibration due dates for recalibration. Ensure replacement instruments are placed into the kits during the calibration period.

- Inventory the Emergency Response kit every month or at least one week prior to a $C S$ shipment. All functional items in the kit will be tested, (e.g., flashights, tape recorder, instruments, calculator). Document this inventory noting any missing/damaged items. Report any deficiencies to the OHM Project Manager and correct them.

- Ensure each team member knows where the equipment is being stored, has all of the necessary keys and security clearance to access the equipment, and can make arrangements for emergency traver and accommodations.

\subsection{EMERGENCY RESPONSE TEAM ORGANIZATION}

The Emergency Response team is a coordinated function of OHM to provide advanced-level radioactive materials mitigation capability. The Emergency Response team will observe the conditions and make recommendations to TSMT. Command of the emergency is under the local jurisdiction Incident Command.

A team of trained OHM personnel shall be prepared to perform one or more of the functions listed below. The team shall consist of three members. One of the team members shall be a qualified Radiation Control Supervisor. The other two team members are the Project Radiological Engineer and the OHM Project Manager. The OHM Project Manager shall be designated as the Team Leader. This team will be available for rapid mobilization should an emergency situation arise.

The Team Leader shall:

1. Assess and classify the severity of the emergency and initiate this general plan. Determine status of the emergency and send personnel to the accident site as deemed appropriate. Contact TSMT to provide information, recommendations, and relay OHM's proposed response actions.

2. Assign qualified personnel to the Emergency Response team and instruct them to proceed to a pre-response location or the emergency site and perform such actions as deemed necessary.

3. Coordinate emergency operations by maintaining communications with authorized TSMT personnel, local civil authorities on the scene, authorities in the involved States on the scene, OHM Health Physics, $O H M$ Management, and the Emergency Response team.

4. Assume supervision and control of the Emergency Response team at the accident site, or alternate site as deemed appropriate. 


\section{WHC- $M R-0523, R E W . O$ \\ CESIUM TRANSPORTATION PLAN Rev. 0 June 1996}

5. Arrange transportation service for Emergency Response team personnel as required (e.g., air transportation, pickup at airport by State Police, etc.).

6. Support Emergency Response team at accident site by providing for additional assistance, equipment, and/or relief of personnel as required.

\subsection{SKILLED SUPPORT PERSONNEL}

Take actions as directed by the Team Leader or designee and other appropriate actions as required to stabilize the situation and protect individuals from injury and contamination.

\subsection{TRAINING}

The training program shall be administered by OHM. All training shall be documented in accordance with $\mathrm{TN}-002$, Training Procedure.

\subsection{TEAM MEMBER PREREQUISITE QUALIFICATIONS}

\subsubsection{Team Leader}

" Shal1 have experience on one of the Cs recovery projects.

" Must regularly update themselves on proper procedures, available support, and effective regulations.

- Be cognizant of how the shipping package is maintained, handled, and transported.

\section{1 .2 The Team}

- At least three years' experience in radiation/contamination monitoring controls.

- Each new team member must undergo a procedural orientation. Documentation of this orientation is a statement of completion from a Team Leader.

- Each team member that will respond to the accident scene shall participate in any WHC, Western Governors Association (WGA), Midwestern, Southern States Energy Board (SSEB), or DOE sponsored emergency response drills.

- Refresher training of procedural requirements shall be performed annually. Records of this training shall be kept by the OHM Project Manager. 
WHC-MR-0523, REV. 0

CESIUM TRANSPORTATION PLAN

Rev. 0 June 1996

\subsection{NOTIFICATION}

\subsection{REQUEST FOR RESPONSE}

Request for response of the Emergency Response team may originate from TSMT. $\mathrm{He}$ or she may request the response through Anderberg Communications by calling:

EMERGENCY 1-800-925-4959

PAGERS

$\begin{array}{lc}\text { Personnel } & \text { Digital PIN \# } \\ \text { Jeff Stevens } & 105-9575 \\ \text { Steven McQueary } & 105-9573 \\ \text { Walter Paulson } & 105-9574 \\ \text { Wayne Gaul } & 105-9577\end{array}$

Anderberg Communications will then contact the team members using the pagers or phone lines at homes/offices.

- OHM office in Denver, CO (303) 371-8252

- OHM office in Columbia, SC (803) 256-1555

Anderberg Communications will also be given a list of the team members' home phone numbers.

Anderberg Communications will contact the team members and relay the information taken by the person reporting the emergency, and notify each member contacted of the other members that were also successfully contacted.

Additional response members 1 isted below will be contacted on an as-needed basis:
Joe Harverson
(518) $395-7582$
David Higgins
(518) $395-7582$

\subsection{EMERGENCY RESPONSE TEAM}

After notification by Anderberg Communications, the Team Leader, and members will gather at the OHM office in Denver, CO or Columbia, SC. The Team Leader will call Anderberg Communications and inform them that the entire team has gathered and can be contacted at the OHM Offices. 


\subsection{NON-OHM SUPPORT}

other emergency support may be notified by the local jurisdiction incident commander when deemed necessary.

\subsection{STATE AND FEDERAL AGENCIES}

State and/or federal agencies shall be notified by TSMT or OHM Corporate Management when deemed necessary. Note: An incident report shal] be initiated in accordance with SF-016, Incident Reporting Procedure.

\subsection{IMPLEMENTATION}

\subsection{TEAM LEADER}

The Team Leader shall provide the following basic instructions to the incident commander for prevention of radiation exposure. Instructions should be given to the incident commander by phone prior to the team traveling to the scene.

\section{1 .1 Instructions}

1. Isolate area $1,000 \mathrm{ft}$ from truck, containers, or radioactive source until a radiation survey has been taken.

2. Take care of the injured as necessary by using first aid and/or calling an ambulance service. In almost all emergency cases, risking individuat exposure is acceptable when serious or life-threatening injury is involved.

3. Brief the incident commander on the nature of the $C s$ shipments, the type of package, and signs that would indicate package failure.

4. Ensure that the incident commander can communicate with the team as necessary for radiological advice and a communication system is available for further instructions and status reports.

\subsection{TEAM LEADER ACTION}

The Team Leader or designee shall take the following actions after notification of an emergency:

- Determine a specific plan of action and classification of emergency.

- If possible, collect additional information and relay further instructions by telephoning TSMT personnel or the local incident commander at the scene of the incident, and informing the incident commander of what actions to expect from the Emergency Response team.

- Gather the emergency equipment. 
WHC-MR.0S23, KEV. C

CESIUM TRANSPORTATION PLAN Rev. 0 June 1996

- Instruct and dispatch selected Emergericy Response team members and equipment to the accident site or other point of assembly. Determine the most effective mode of transportation to the emergency (e.g., air travel or driving).

- Notify TSMT personnel that the emergency plan is in effect, assistance is en route, what route and mode of transportation taken, the team members and equipment en route, and the estimated time of arrival at the scene.

- Assist local authorities in emergency activities and keep corporate Management advised of the situation.

\subsection{COORDINATION WITHIN THE LOCAL INCIDENT COMMAND SYSTEM}

During response, Emergency Response team members should provide data available on the hazard.

Emergency response actions are performed at the direction of the Team Leader in coordination with the TSMT representative. If Utility, State, or County emergency response plans exist and are in action, the use of this procedure will be limited to administrative actions.

The Emergency Response team will operate within the local jurisdiction incident command system (ICS) as the Emergency Response group for TSMT.

\subsection{STAGING}

The arriving Emergency Response team will contact the TSMT representative at 1-800-234-8768, and local jurisdiction's incjent command as to the location of staging for all other Emergency Response team units. Staging locations should account for the following criteria:

- Evaluate the situation

- Stage uphi11, upwind

- Be in a safe location

- Have adequate access to the scene

- Stay out of the way of other units that are operating in the area

\subsection{INCIDENT COMMAND}

Note: Continuous progress reports must be provided to the TSMT representative, local jurisdiction incident commander, and Emergency Response group supervisor in his/her absence from scene by the designated Team Leader during the course of the incident.

The Emergency Response team was created to provide the existing emergency management resources with trained personnel and equipment for radiological emergencies. OHM Emergency Response toam will operate under local jurisdictions' ICS. 


\section{WHC- $M K-0523, K E \% . O$ \\ CESIUM TRANSPORTATION PLÁN Rev. 0 June 1996}

- The TSMT representative or local jurisdiction incident commander at an emergency will call for the Emergency Response team when deemed necessary.

The Team Leader/designee will coordinate activities through the TSMT representative and incident commander. They will cooperate fully with local jurisdiction to mitigate hazards.

\subsection{COMMUNICATION}

General provisions during emergency response - Emergency Response team

Al1 communications shall be in plain English. When spelling substance names, conventional phonetics shall be used.

\section{Phonetic Alphabet}

$\begin{array}{lll}\text { A - Alpha } & \text { J - Juliet } & \text { S - Sierra } \\ \text { B - Bravo } & \text { K - Kilo } & \text { T - Tango } \\ \text { C - Charlie } & \text { L - Lima } & \text { U - Uniform } \\ \text { D - Delta } & \text { M - Mike } & \text { V - Victor } \\ \text { E - Echo } & \text { N - November } & \text { W - Whiskey } \\ \text { F - Foxtrot } & \text { O-Oscar } & \text { X- X-Ray } \\ \text { G - Golf } & \text { P - Papa } & \text { Y - Yankee } \\ \text { H - Hotel } & \text { Q - Quebec } & \text { Z - Zulu } \\ \text { I - India } & \text { R - Romeo } & \end{array}$

The Team Leader shall confirm the designation of a clear radio channel with the TSMT representative and incident commander or a dedicated phone 1 ine to the TSMT Office. The Emergency Response kit contains two hand-held CB radios that can be used for on-scene communications.

After the initial briefing session between the incident commander or TSMT representative and Team Leader, the Team Leader shall remain in contact with the TSMT representative. TSMT has designated the following personnel as authorized to direct $0 \mathrm{HM}$ 's actions at the scene:

TSMT Facility

Jeff Cooney

Troy Highland

Dave Lambert

Bi11 Rucker

Ben Southwick
Director of Safety and Compliance

TRANSCOM Coordinator

Director of Driver Training

Radioactive Materials QA Mgr.

Vice President, Safety
$800-234-8768$

(417) $781-7158 \mathrm{Hm} \mathrm{Ph}$

(417) 782-1149 $\mathrm{Hm} \mathrm{Ph}$

(417) $782-5136 \mathrm{Hm} \mathrm{Ph}$

(417) 673-1000 $\mathrm{Hm} \mathrm{Ph}$

(417) 781-1035 $\mathrm{Hm} \mathrm{Ph}$

In addition, the TSMT on-call corporate representative shall also be authorized to direct $0 \mathrm{HM}$ 's action at the scene.

The Team Leader or designee shall be responsible for the following communications-related duties: 
WHL-WK-0523, KEV

CESIUM TRANSPORTATION PLAN Rev. 0 June 1996

1. Monitor all communications during the recovery for requests of assistance, indications of personnel distress, or any other emergency transmissions.

2. Monitor all communications with the other recovery team personnel.

\subsection{ESTABLISHING THE INTERACTION WITH THE ICS}

The Emergency Response team will inform the ICS that they are here as the Emergency Response team part of TSMT and are responsible for directing the cleanup of the scene and the recovery of the shipment. The Team Leader or designee shall leave the Emergency Response Staging area and report to TSMT and the local jurisdiction incident commander and shall relate any pertinent information or advice that he/she has for that stage of incident. During this briefing session, the Team Leader or designee shall review with the local jurisdiction incident commander the actions that have been taken thus far, and those tasks that need to be completed in the immediate future. A review shall include:

- The identification of material and shipping container involved. A briefing on the shipment.

- Designation of a "clear" tactical channel or channels in order to manage the incident.

- The need for additional resources/outside agencies.

- The steps being taken to close off access to the incident site (the closing of roads and intersections).

- The measures being taken to isolate the radiological materials (the establishment of zones - Fire and Hazardous).

- Establishment and location of "Access Control."

- The need for evacuation.

- The identification of key civilian personnel.

- An assessment of the location of command and other units at the scene or in staging areas. Ensure their safety from contamination, exposure, explosion, or toxic exposure.

- The proper level of protective clothing for emergency service personne1.

- A review of the tasks assigned to units at the scene.

- The need for radiation exposure management and medical treatment.

\subsection{RESPONSE ACTIONS WITHIN THE LOCAL ICS}

The Emergency Response team shall perform the following actions as requested by the TSMT representative and the incident commander. 


\section{WHC- $M E-0523, K_{E V} \cdot O$ \\ CESIUM TRANSPORTATION PLAN ReV. 0 June 1996}

\subsection{EVALUATION}

1. Conduct radiation surveys at the perimeter of area and work in toward the cask.

2. Perform an inspection of the truck, trailer, and cask to determine what damage has occurred and the extent of the damage.

3. The normal radiation levels on the loaded cask are as follows:

$\begin{array}{lll}\text { Lid Seal and Bolt Holes: } 15-20 & \mathrm{mrem} / \mathrm{hr} \\ \text { Cask Body: } & 5-10 & \mathrm{mrem} / \mathrm{hr} \\ \text { Upper Port: } & 25 & \mathrm{mrem} / \mathrm{hr}\end{array}$

\subsection{SITE ENTRY}

The incident commander will grant permission to the team to make an area entry and should specify what precautions for non-radiological hazards should be taken. General procedure for entry of area:

1. Personnel shall be equipped with personnel monitoring devices (thermal luminescence dosimeters [TLDs] and pocket dosimeters).

2. Enter accident area with radiation survey instruments in operation (any indication of radiation levels above normal background would suggest possible damage and release of internal contents of the cask).

3. Exercise judgement using all available data and information in the need to wear protective clothing and respiratory protection. Visually inspect area from a distance to determine if leakage is apparent.

4. Site entry is addressed during primary assessment because of the need for survey and reconnaissance of the emergency site. Due to the nature of the material and the package containing it, radioactive contamination is highly unlikely.

a. Eating, drinking, chewing gum or tobacco, smoking or any practice that increases the probability of hand-to-mouth transfer and ingestion of material is prohibited.

b. Whenever decontamination procedures for outer garments are in effect, the entire body should be thoroughly washed as soon as possible after the protective garment is removed.

c. Contact with contaminated or suspected contaminated surfaces should be avoided. Whenever possible, do not walk through puddles, leachate, discolored surfaces, kneel on ground, lean, sit or place equipment on drums, or place containers on the ground.

d. Medicine and a1cohol can potentiate the effects from exposure to toxic chemicals. Prescribed drugs should not be taken by personnel on response operations where potential for absorption, inhalation, or ingestion of toxic substance exists unless specifically approved by a qualified physician. 
WHC- MR-0523, KEV.O

CESIUM TRANSPORTATION PLAN Rev. 0 June 1996

e. Any required respiratory protective devices and clothing must be worn by all personnel going into areas designated for wearing protective equipment.

f. Onsite personne? must use the buddy system when wearing respiratory protective equipment. As a minimum, a third person, suitably equipped as a safety backup, is required during initial entries. A two-man safety team is the goal.

g. Radio contact must be maintained between pairs onsite and safety personnel. Entry team members shall remain close together to assist each other during emergencies.

h. During continual operations, onsite workers act as safety backup to each other.

i. Personnel shall practice unfamiliar operations prior to doing the actual procedure.

j. Entrance and exit locations must be designated and emergency escape routes delineated. Warning signals for site evacuation must be established.

k. Communications using radios, hand signals, signs, or other means must be maintained between initial entry members at all times. Emergency communications shall be prearranged in case of radio failure, necessity for evacuation of site, or other reasons.

\subsection{Survey and Reconnaissance}

The team initially entering the site is to accomplish one or more of the following objectives:

- Determine or verify the hazards that exist or that may potentially exist, affecting public health, the environment and response personne?.

- Verify existing information and/or obtain information about the incident.

- Evaluate the need for prompt mitigation.

- Collect supplemental information to determine the safety requirements for personnel initially and subsequentry entering the site.

Before the team enters the site, as much information as possible shall be collected (depending on the time available) concerning the types of hazard(s), degree of hazard(s), and risks which may exist. Based upon available information (shipping manifests, transportation placards, existing records, container labels, etc.) or offsite studies, the team assesses the hazards, determines the need to go onsite and identifies initial safety requirements.

The initial onsite survey is to determine, on a preliminary basis, hazardous or potentially-hazardous conditions. The main effort is to rapidiy identify the immediate hazards that may affect the public, response personnel, and the 
environment. Of major concern are the real or potential dangers from fires, explosion, radiation, and oxygen-deficient atmosphere.

In general, the initial entry is considered a relatively rapid screening process for collecting preliminary data of site hazards. The time needed to conduct the initial survey depends on the urgency of the situation, type of incident, information needed, size of the site, availability of resources, and level of protection required for initial entry personnel. Consequently, initial surveys may need hours to complete and consist of more than one entry.

\subsubsection{Priority for Initial Entry Moritoring}

of immediate concern to initial entry personnel are atmospheric conditions which could affect their immediate safety. These conditions are airborne toxic substances, combustible gases or vapors, lack of oxygen, and ionizing radiation. Priorities for monitoring these potential hazards shall be established after a careful evaluation of conditions.

When the type of material involved in an incident is identified and its release into the environment suspected or known, the material's chemical/physical properties and the prevailing weather conditions may help determine the order of monitoring. An unknown substance or situation presents a more difficult monitoring problem.

For open, well-ventilated areas, combustible gases, and oxygen deficiency are lesser hazards, and require lower priority. However, areas of lower elevation onsite (such as ditches and gullies) and downwind areas may have combustible gas mixtures, in addition to toxic vapors or gases, and lack sufficient oxygen to sustain life. Entry teams shall approach and monitor whenever possible from the upwind area.

\subsubsection{Periodic Monitoring}

The monitoring surveys made during the initial site entry phase are for a preliminary evaluation of atmospheric hazards. In some situations, the information obtained may be sufficient to preclude additional monitoring (for example, a radioactive material package determined to be releasing no radioactive material). Materials detected during the initial site survey may call for a more comprehensive evaluation of hazards and analyses for specific components. A program may be established for monitoring, sampling, and evaluating hazards for the duration of site operations. Since site activities and weather conditions change, a continuous program to monitor atmospheric changes must be implemented utilizing a combination of stationary sampling equipment, personal monitoring devices, and periodic area monitoring with direct-reading instruments. 
WHC-MK-OS23, KEV.C

CESIUM TRANSPORTATION PIAN ReV. 0 June 1996

\subsubsection{Ambient Atmospheric Concentrations}

Any indications of atmospheric hazards - toxic substances, combustible gases, lack of oxygen and radiation - shall be viewed as a sign to proceed with care and deliberation. Readings indicating explosive atmospheres or high concentration of toxic substances may change the associated risks and extreme caution should be exercised in continuing surveys when any atmospheric hazards are indicated.

\subsubsection{Levels of Protection}

Equipment to protect the body against contact with known or anticipated toxic contaminants have been divided into four categories according to the degree of protection afforded:

Level A - Shall be worn when the highest level of respiratory, skin, and eye protection is needed.

Level B - Shall be worn when the highest level of respiratory protection is needed, but a lesser level of skin protection.

Level C - Shall be worn when the criteria for using air-purifying respirator (APR) are met.

Level D - Shall be worn only as a work uniform and not on any site with respiratory or skin hazards. It provides no protection against contaminant hazards.

The level of protection selected shall be based on:

1. Type and measured concentration of the substance in the ambient atmosphere and its toxicity.

2. Potential for exposure to substances in air, splashes of liquids, or other direct contact with material due to work being done.

The situations where the type of material, concentration and possibilities of contact are not known, the appropriate level of protection must be selected based on professional experience and judgement until the hazards can be better identified.

\subsection{ENTRY TEAM REQUIREMENTS}

The designation "Entry Team" means any team member who is a part of the Entry Team or who has responsibility for dressing or monitoring team personnel that enter the Exclusion Zone. Each team member that is placed in protective equipment shall be dressed-out according to the following instructions. 
$\omega H c-M k-O S \alpha 3, k \in V . O$

CESIUM TRANSPORTATION PLAN Rev. 0 June 1996

\subsubsection{Dress-0ut Instructions}

1. A verification that the protective clothing is appropriate for materials that are to be controlled.

2. A check of the self-containing breathing apparatus (SCBA), air cylinder gauge and/or APR.

3. A verification that the proper boots and gloves are being worn.

4. A check for double gloving.

5. A visual check of the suit for defects.

6. A physical check that the suit closure is fully closed. secured and properly sealed.

7. A full communication check for designated "Entry Team" personne?.

\subsubsection{Communications Check Between Personnel}

Once Entry teams are suited up, a communications check will take place among all members who have communications responsibilities. This system check would include the Entry team, the Entry Team Leader, and the Emergency Response group supervisor or designee.

\subsubsection{Communication Check Points}

A communication check will occur at given location points as follows:

Note: The Entry Team Leader should maintain visual contact whenever possible.

1. Before the Entry Team enters the Exclusion Zone.

2. At the Exclusion Zone when ongoing communications are not occurring prior to entrance into the Exclusion Zone.

3. Prior to the Entry Teams entering the decontaminating area (if applicable).

\subsection{WORK ZONES}

At the earliest possible stage of a radioactive materials incident, work zones should be established:

Zone 1: Exclusion Zone

Zone 2: Contamination Reduction Zone

Zone 3: Support Zone

\subsubsection{Zone 1: Exclusion Zone}

This is the area where radiation/contamination does or could occur.

All personnel entering the Exclusion Zone must wear prescribed levels of protection.

Entry and exit check points must be established at the periphery of the Exclusion Zone for control of the flow of personnel and equipment. 


\section{$W H C-M K-C .523, A E \%$ \\ CESIUM TRANSPORTATION PLAN Rev. 0 June 1996}

The outer boundary of Zone $l$ is called the Hotline. The Hotline is established by visually surveying the immediate environments of the incident and determining where the hazards involved are located including drainage. Additional factors that should be considered include the distances needed to prevent fire or an explosion from affecting personnel outside the zone, the physical area necessary to conduct site operations, and the potential for contaminants to be blown from the area.

The Hotline should be physically secured with marker tape or some type of visible landmarks.

Identify and post areas in accordance with the following:

- Rope off and post "Radiation Area" signs in all areas where radiation level exceeds $2 \mathrm{mrem} / \mathrm{hr}$.

- Post "High Radiation Area" signs in all areas which exceed 100 $\mathrm{mrem} / \mathrm{hr}$.

\subsubsection{Zone 2: Contamination Reduction Zone}

This zone serves as a buffer between the Exclusion Zone (Zone 1) and the support area (Zone 3). Initially, this area is non-contaminated. The decontamination areas are in this non-contaminated zone. As operations proceed, the area around the decontamination stations may become contaminated but to a much lesser degree.

The boundary of the Contamination Reduction Zone is called the Contamination Control Line. This line is also marked by tape or some other physical barriers.

\subsubsection{Zone 3: Support Zone}

The Support Zone, the outermost part of the site, is considered a noncontaminated or clean area. Support equipment (Command Post, equipment trailer, etc.) is located in this zone; traffic is restricted to authorized response personnel. Since normal work clothes are appropriate within this zone, potentially-contaminated personnel clothing, equipment, and samples are not permitted, but are left in the Contaminant Reduction Zone until they are decontaminated.

The location of the Command Post and other support facilities in the Support Zone depend on a number of factors, including:

Accessibility: Topography; open space availability; locations of highways, railroad tracks; or other limitations.

Wind Direction: Preferably the Support Facilities should be located upwind of the Exclusion Zone. However, shifts in wind direction and other conditions may be such that an ideal location based on wind direction alone does not exist.

Resources: Adequate roads, power 1ines, water, and shelter. 


\section{WHE-MR-052 3, KEV. O \\ CESIUM TRANSPORTATION PLAN Rev. 0 June 1996}

\subsubsection{Other Considerations for Work. Zones}

Other skilled personnel within the ICS may have to perform functions under consideration.

Modifications - The use of a three-zone system, access control points, and exacting decontamination procedures provides a reasonable assurance against the trans-location of contamination substances. This site-control system is based on a worst-case situation.

Less stringent site control and decontamination procedures may be utilized if more definitive information is available on the types of substances involved and hazards they present. This information can be obtained through air monitoring, instrument survey and sampling, and technical data concerning the characteristics and behavior of the material present.

Area Dimensions - The distance between the Hotline, Contamination Control Zone, and Command Post and the size and shape of each zone have to be based on conditions specific to each site. Considerable judgement is needed to assure that the distances between zone boundaries are large enough to allow room for the necessary operations, provide adequate distances to prevent the spread of contaminants, and eliminate the possibility of injury due to explosion or fire. Long-term operations would involve developing reasonable methods (for example, air surveillance, swipe-testing and visible deterioration) to determine if material is being transferred between zones and to assist in modifying site boundaries.

The following criteria should be considered in establishing area dimensions and boundaries:

- Physical and topographical features of the site

- Weather conditions

- Field measurements of air contaminants and environmental samples

- Air dispersion calculations

- Potential for explosion and flying debris

- Physical, chemical, toxicological and other characteristics of the substances present

- Clean-up activities required

- Potential for fire

- Area needed to conduct operations

- Decontamination procedures

- Potential for exposure

- Proximity to residential or industrial areas

- Monitoring and sampling.

To verify that site control procedures are preventing the spread of contamination, a monitoring and sampling program should be established. Support Zone should be periodically monitored for air contaminants, using direct-reading instruments and collecting air samples for particulate, gas, or vapor analysis. Analysis of soil samples collected in the most-heavily used area would indicate contaminants being carried from the Exclusion Zone by personnel, equipment, or wind. Occasional swipe tests should be taken in trailers and other areas used by personnel. 


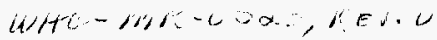

CESIUM TRANSFORTATION PLFN Rev. 0 June 1996

These same types of samples should be collected and air-monitored in the Contamination Reduction Zone. Increased concentrations in air or other environmental media may indicate a breakdown in control over the Contamination Reduction Corridor, ineffective decontamination procedures, or failure to restrict site access.

Figure 1. Diagram of Site Work Zones.

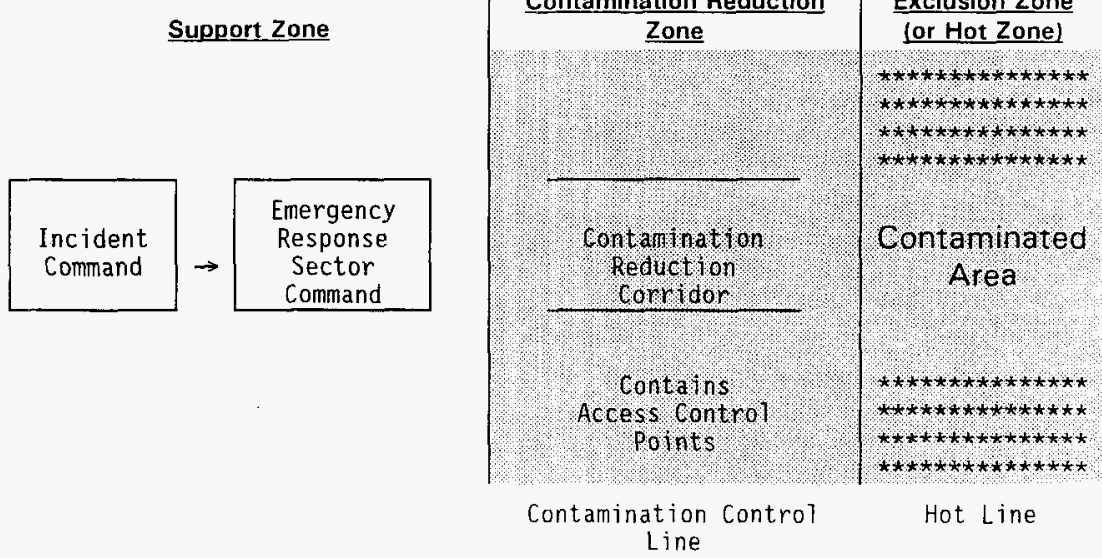

\subsection{PROTECTIVE ACTION}

The degree of protective action depends on the severity and classification of emergency.

Visually inspect the scene at the emergency from a reasonable distance for any apparent outward signs of damage.

\subsection{DECONTAMINATION}

Personnel responding to Radioactive Materials Incidents may become contaminated in a number of ways, including:

- Contacting vapors, gases, mists, or particles in the air

- Being splashed by materials while sampling or opening containers

- Walking through puddles of liquids or on contaminated soil

- Using contaminated instruments or equipment.

Decontamination consists of physically removing contaminants. How extensive decontamination must be depend on a number of factors: the most important being the type of material involved. The more toxic the material, the more extensive the decontamination processes. 


\section{$W H C-M A-0523,1 E V . O$ \\ CESIUM TRANSPORTATION PLAN Rev. 0 June 1996}

Only general guidance can be given on methods and techniques for decontamination.

\subsection{CONTAMINATION REDUCTION CORRIDOR}

An area within the Contamination Reduction Zone is designated the Contamination Reduction Corridor (CRC). The CRC controls access into and out of the Exclusion Zone and confines decontamination activities to a limited area. The size of the corridor depends on the number of stations in the decontamination procedure, overall dimensions of work control zones, and amount of space available at the site. A corridor of 75 feet by 15 feet should be adequate for full decontamination. Whenever possible, it should be a straight path.

The CRC boundaries should be conspicuously marked, with entry and exit restricted. The far end is the Hotline - the boundary between the Exclusion Zone and the Contamination Reduction Zone. Personnel exiting the Exclusion Zone must go through the CRC. Anyone in the CRC should be wearing the level of protection designated for the decontamination crew. Another corridor may be required for heavy equipment needing decontamination. Within the CRC, distinct areas are set aside for decontamination of personnel, portable field equipment, removed clothing, etc. These areas should be marked and personnel restricted to those wearing the appropriate level of protection. Al1 activities within the corridor are confined to decontamination.

\subsection{RECORDS AND REPORTS}

An incident report shall be submitted by the Team Leader in accordance with SF-016, Incident Reporting Procedure.

OHM sha7l make any formal report of their actions and submit the report to TSMT.

The Team Leader will provide information to state and local officials on the scene only as needed. All additional information to the local or state on-the-scene officials shall be provided by TSMT. Information to the press and public shall only be made by TSMT or OHM Corporate Officials or their designee(s) (SF-017, Incident Investigation Procedure).

Emergency Response team members shall make themselves available to TSMT and/or their agents and representatives to describe their actions and the incident response if necessary.

All tape-recorded logs of the incident and response shall be transcribed. The tapes and transcriptions shall be retained.

\subsection{FOLLOW-UP}

The Team Leader shall report the radiological status to OHM Corporate Management and advise of protective action placed in effect or required. 
WHC- MR- $0523, K E V . O$

CESIUM TRANSPORTATION PLAN Rev. 0 June 1996

The Team Leader shall report to OHM Corporate Management any physical damage and specify handling instructions if required.

If radiation and/or contamination is involved:

1. Contact and monitor all persons who may have been exposed and/or contaminated (record names and addresses).

2. Keep records of all actions, survey results, exposures, names of personnel involved, and contacts for formal report preparation.

An Emergency Response team member shall remain in attendance until the incident is either removed from its emergency status, restored to norma] condition, and/or as instructed by TSNT.

The Emergency Response group supervisor shall prepare a final report containing all the appropriate records and reports and shall submit the report to the OHM Document Control for lifetime retention.

\subsection{EMERGENCY INSTRUCTIONS TO TSMT DRIVERS}

In order to determine the proper response to an accident or incident involving the Cs shipments, it is imperative that such response be based upon detailed, factual information. The gathering and dissemination of such information shall be the primary function of the TSMT drivers. These instructions are also applicable to the Emergency Response team when they arrive at the scene:

1. Safeguard yourself and others - keep everyone but law enforcement officials and regulatory personnel clear of the area.

2. Protect the scene by setting up warning signals to prevent further incidents.

3. Render first aid or medical assistance to yourself or others as necessary.

4. As soon as possible, the driver shall make all emergency notifications, including local police and fire departments. Notifications must include:

- TCC - Oak Ridge, TN (423) 576-9115

- WHC - Richland, WA (509) 373-3800

- $\mathrm{DOE}$

- Oak Ridge Operations, for the states of VA, WV, KY

(423) 576-1005 or (423) 525-7885

- Chicago Operations, for the states of IN, IL, IA, NE

- Duty Hrs, (312)-972-4800/0ff Hrs, (312) 972-5731

- Idaho Operations, for the states of WY, UT, ID (208) 526-1515

- RL, for the states of OR, WA (509) 373-3800

- TSMT Safety Department - Jop] in, M0 (800) 723-8768

- OHM - Denver, CO (303) 371-8252 Columbia, SC (803) 214-2160

- Appropriate State/Tribal Authority: 


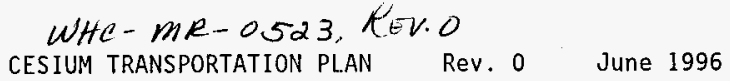

\begin{tabular}{|c|c|c|c|c|c|c|c|c|}
\hline VA & $(804)$ & $674-2400$ & IL & (217) & $785-9868$ & UT & $(801)$ & $965-4505$ \\
\hline WV & $(304)$ & $746-2111$ & IA & (515) & $281-3231$ & ID & $(208)$ & $736-3060$ \\
\hline KY & $(502)$ & $564-7815$ & NE & $(402)$ & $471-4545$ & OR & $(503)$ & $378-2575$ \\
\hline IN & $(800)$ & $669-7362$ & WY & $(307)$ & $777-4321$ & WA & $(509)$ & $575-2323$ \\
\hline & ted & ribes & & 17 & iar & & $(503)$ & $278-055$ \\
\hline
\end{tabular}

Note: The VSP Duty Sergeant should be notified [(804) 674-2026] during emergency situations if the situation is security related and the Department of Emergency Services [(804) 674-2400] for life threatening situations.

5. Make yourself readily available to fire and 1 aw enforcement personnel when they arrive at the scene.

6. Continue to update at reasonable intervals a 11 companies and governmental agencies whenever practical.

$C B$ radios will monitor channel 19 for routine communications between the truck and escort vehicle. Channel 9 will be utilized in emergency situations to communicate with state and local authorities.

In the event of an incident/accident, your cooperation with the TSMT Safety Department, OHM, WHC, DOE, DOT, state and local authorities is critical for recovery operations. Requests for information by anyone other than those identified in this statement must be referred to:

Terry Brown - RL - (509) 376-8189

Karen Randolph - RL - (509) 376-8230

Guy Schein - RL - (509) 376-0413

Judy Graybeal - WHC - (509) 376-2472 (Home) (509) 582-0647

TSMT Safety Department - (800) 723-8768

7. Do not allow any person to pick up or otherwise handle any material involved with the scene until authorized to do so by the appropriate oHM and/or governmental official.

8. Allow only those persons absolutely necessary to deal with the emergency to remain in the area. Keep all bystanders at a minimum of $1000 \mathrm{ft}$ away and upwind.

9. Stay out of smoke, mist, dust, or other visible airborne substances.

10. Fight fire from upwind where possible and treat it as involving toxic fumes.

11. Do not eat, drink, smoke, or allow open flames in the immediate area.

12. Follow the instructions of the Emergency Response Guide $\# 64-1993$

Edition. Regulatory personnel wit7 determine the next appropriate actions at the scene. 


\section{WHC-MR - 0523, REV.O \\ CESIUM TRANSPORTATION PLAN Rev. 0 June 1996}

13. Any clothing or equipment that becomes damaged or contaminated must be segregated and saved for later decontamination or disposal.

14. Remain at the scene and available until the emergency is declared over and you are released by both law enforcement officials and regulatory agency personnel.

15. Do not touch anything that will be eaten or otherwise ingested before thoroughly washing hands.

16. A written report as required by 49 CFR 171.16 will be sent to DOT by the TSMT Safety Department in Joplin, MO.

\subsection{TSMT EMERGENCY RESPONSE ORGANIZ.ATION}

TSMT personne] will be on duty in the Safety Department during normal business hours and Safety personnel will be on duty (other than normal working hours) at the gate in Joplin, M0. To report any incident call (800) 723-8768.

\subsection{OHM EMERGENCY RESPONSE ORGANIZATION}

- OHM has set up a 24-hour notification service. The service can be contacted at (800) 925-4959. The answering agent will collect the necessary information and notify the OHM standby Emergency Response team members. The team members are notified by a pager service (800) $796-7363$.

- During business hours, the OHM Office in Columbia, SC, can be contacted at (803) 256-1555.

- During business hours, the OHM Office in Denver, CO, can be contacted at the OHM office at (303) 371-8252.

- After-hours contacts:

- Jeff Stevens AREC0/Escort Project Manager Home: (303) 644-3350

Pager Identification Pin Numbers: 555-1387 (a)pha)/105-9575 (Digital)

- Steven McQueary Project Supervisor

Home: (303) 644-3621

Pager Identification Pin Numbers: 555-5131 (Alpha)/105-9573 (Digital) 
WHC- MR $-0523, T E V . O$

CESIUM TRANSPORTATION PLAN Rev. O June 1996

\subsection{CS CASK RECOVERY GUIDE}

\subsection{INTRODUCTION}

a. This guide addresses proposed steps to be taken for recovery operations resulting from a highway accident or incident involving the BUSS cask.

b. State, tribal, and local governments have statutory responsibility for command and control of an incident/accident scene. Should the state desire, DOE assistance may be provided by calling the appropriate DOE office identified in Section 16.0, Item 4 (Notifications).

\subsection{SCOPE}

a. To ensure availability of this guide for the duration of the Cs shipments, a copy wil] be carried in the cab of each TSMT tractor, provided to each state/tribe-designated location, each DOE Emergency Response Center, and the TCC.

b. This guide provides general recommendations for cask recovery operations. Specific actions will need to be tailored to fit actual incident/accident conditions encountered.

c. This guide is intended to address the cask recovery operation aspect and assumes that any actions to save lives have been initiated and completed.

d. Cask recovery and the subsequent Environmental Remediation will take place only after the accident/incident scene has been secured and stabilized.

i. For the purpose of this guide, "stabilized" means the following:

(1) Appropriate emergency response plans have been implemented, based on severity of accident/incident.

(2) Any injured persons have been treated.

(3) Fire, or the threat of fire, has been eliminated.

(4) Radiation surveys have been conducted and sources, locations, and strengths of direct radiation and/or radioactive contamination, if any, have been identified.

(5) Exclusion areas have been established and emergency response personnel have control of the accident scene.

(6) The incident commander and emergency response authorities have given permission to proceed with the cask recovery operation. 


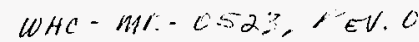

CESIUM TRANSPIRTATION PLAN Rev. 0 June 1996

ii. General:

(1) At the direction of the incident commander, or the statedesignated representative, a radiation survey will be made prior to implementation of recommendations within this guide.

(2) Once the area is determined to be radiologically controlled, recovery operations may begin.

(3) If contamination is encountered which could preclude initiation of recovery activities, the incident commander or statedesignated representative should be advised to contact the DOE for assistance.

(4) Any cleanup required is the responsibility of TSMT through their subcontractor, OHM, and should be performed in consultation with WHC and DOE in cooperation with the state/tribal authority to ensure proper cleanup levels. Payment of costs for recovery and cleanup is provided by TSMT and is evidenced by a certificate of insurance and MCS-90 on file with WHC.

e. Recovery activities must be performed with an accompanying health physics technician, calibrated radiation monitoring instruments, and appropriate protective clothing and breathing devices.

f. With permission from the incident commander, cask recovery activities may begin. These activities consist of the following:

(1) Cask access

(2) Cask damage inspection and assessment

(3) Recovery resource determination

(4) Recovery operations

(5) Post-recovery cleanup

\subsection{INSPECTION AND RECOVERY PROCEDURES}

a. General:

i. Recovery of a damaged tractor and/or trailer is a carrier responsibility and must be accomplished using a commercial wrecking/crane service. (See list in Appendix B, Attachments C and D)

ii. The recovered cask will be sent to a location identified by the incident commander or state/tribal-designated representative.

iij. In all cases an evaluation will be made by the TSMT Safety Department, $O H M$, WHC, and DOE, to determine whether the package involved in an accident/incident still meets the certification criteria for future use. Note: Extreme cask damage resulting in loss of containment is highly unlikely. Recovery operations for this improbable circumstance are beyond the scope of this document 


\section{WHC- MA - O - 23, A-EV.C}

CESIUM TRANSPORTATION PLAN Rev. 0 June 1996

\section{and would involve other plans such as the Federal Radiological Emergency Response Plan (FRER).}

iv. If the cask is an obstacle to the orderly, safe flow of traffic, and if radiation levels do not exceed DOT limits, the package may be moved to the side of the road to allow traffic to pass.

b. Approaching the Cask: In a severe accident condition it will be necessary to inspect the cask.

c. Gaining Access to the Cask: If the cask is obscured by wreckage, buried or partially buried in soil, or submerged in water, then it may take special means to gain access. If a radiation survey determines that there is no gross loss of shielding or containment then "hands-on" methods can be employed.

i. Wreckage obscuring the cask can be removed using conventional cutting methods with tow trucks or cranes for lifting or dragging operations.

ii. Care must be taken to avoid disturbing the cask or any structures that support the cask. This removal is only for access.

iii. If the cask is buried, earth removal equipment (e.g., backhoe) can be used to uncover as much as the cask surface as is reasonable without resulting in cask movement. The uncovering of the cask surface will improve the heat displacement. As wreckage is removed, radiation/contamination surveys will be taken to determine if there has been a breach in the cask.

iv. All removed material should be treated as being contaminated until surveyed and released by a health physics technician.

v. If the cask is submerged, it may require diving operations for inspection and recovery. Underwater access could also involve wreckage removal and displacement.

d. Cask Damage Inspection:

i. The shipping papers that accompany the cask identify the transport index and radiation survey data at dispatch and will be available at time of damage inspection.

ii. Once approach to the cask is possible, inspect it to determine the extent of damage and to assess the methods of recovery.

iij. The inspection must be performed and documented by WHC and DOE.

iv. If the accident scene radiation survey indicates normal or near-normal direct radiation readings and no apparent radioactive contamination, then inspection should proceed and will include the following: 
WHC-MK-0523, KEV.C

CESIUM TRANSPORTATION PLLAN Rev. 0 June 1996

(1) BUSS Cask Impact Limiters

(a) The large impact limiters on either of the horizontally/vertically shipped casks are intended to protect the cask from mechanical assault and can be expected to sustain damage in a severe accident. The limiters cover the cask lid and the two vent/drain ports which are prime areas of concern regarding containment integrity.

(b) If the limiters are undamaged, or, if the limiters are in p 7 ace and any damage appears minimal, there can be assurance that the cask 1 id ports are intact. It is not recommended that the limiters be removed. Rather, the removal should be performed when the cask is relocated to a more secure and properly-equipped facility.

(c) If one or both of the limiters are severely damaged or missing, the inspection must proceed to the examination of those components that are exposed. It is recommend not to at tempt removal of the limiter.

(d) There are conditions where it may be necessary to remove the limiter. Three of these are:

(i) Indications that the source of radiation leakage is concealed by the limiter. This situation is beyond the scope of this document and removal of the limiter is not recommended without assessment of the situation by a health physicist.

(ii) The limiter is impeding recovery operations.

(iii) A puncture through a limiter in the vicinity of a port.

(e) If the 7 imiter needs to be removed; the BUSS Cask Operating Manual should be consulted.

(f) The limiters were designed to be removed with the cask in the vertical position. Special rigging is needed for removal in any other orientation, particularly if the limiter is severely damaged. Each limiter weighs approximate 7 y 3,000 $1 \mathrm{~b}$.

(2) BUSS Cask Body and Tiedown Components

(a) The cask is secured to a shipping skid which is bolted to a special single-drop, low-boy trailer. In most cases the skid and cask will remain attached to the trailer. However, in the event of a severe accident the cask will separate from the trailer. 
WHQ-MK - O523, KNV.O

CESIUM TRANSPORTATION PLAN Rev. 0 June 1996

(b) The personnel barrier over the center section of the cask body is mounted on the trailer and may become dislodged under severe accident conditions. Remnants of the personnel barrier must be removed to gain access for inspection. Barrier removal may be accomplished by cutting the mounting bolts.

(3) Cask Body

(a) The BUSS cask is a monolithic stainless steel forging, and only superficial damage is expected under accident conditions. Portions of the body that can be seen between the 7 imiters should be inspected for damage.

(b) When loaded, the cask body will be thermally hot. If the stainless steel fins are blocked by material, earth for example, the fins should be cleaned to permit improved heat displacement. The extent of fin damage should be noted by OHM personnel recording the data. Puncture indications should be radiation surveyed for reduction in shielding effectiveness. Other gross distortions should also be noted.

(4) Lifting/Attachment Components

(a) The cask is secured to the skid through two cask tiedown/lifting trunnions. Each trunnion is connected to the skid by two turnbuckles and a tiedown yoke. These components should be thoroughly examined.

(b) The skid weighs about 3,400 1b and the cask weighs approximately 30,30016 and may have to be lifted as an assembly. The assemb1y may need to be lifted by either component, thus the connection must be intact. Inspection must include the attachment welds to the skid.

(c) Examine turnbuckles carefully. A loose turnbuckle is an indication that some permanent deformation has occurred in the tiedown system. Check the quick release pins between the turnbuckles and skid for deformation.

(d) During the inspection, particular attention should be paid to the bolts that attach the trunnions to the cask body. These trunnions are likely to be the components used for recovery. Note the condition of the two horizontal lifting lugs that are bolted to the cask upper centerline when it is in the normal transportation orientation since these components may also serve as recovery attachment points. 


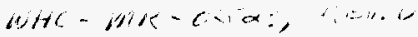

CESIUM TRANSPJRTATION LAA Rev. 0 June 1996

(5) Trailer Attachments

(a) In some cases the trailer may be the only component accessible for initial recovery purposes. If possible, the bolts attaching the skid to the trailer should be inspected for damage. All bolts should be visible, in place, and tight. Any loose or missing bolts suggest that permanent deformation has occurred and the attachment may be in question.

(6) Cask Lid and Penetrations

(a) If there is damage to the impact limiters to the extent that they are missing or severely deformed, as described above, then the cask 1 id and penetrations should be inspected by qualified personnel other than the TSMT/OHM recovery team. This inspection shall be the responsibility of WHC and DOE.

\section{e. Damage Assessment}

i. After inspection, the damage must be assessed to ensure that the recovery operation can be successfully completed. The concern is whether the recovery can be completed without further damaging the cask or contents and causing an increase in direct radiation exposure or a release of contents to the environment.

ii. Certain emergency conditions may require cask transport without being in full compliance with the CoC. Such transport will only be done with approval by the appropriate state/tribal authority. Special implemented precautions (i.e., escorts, speed limits, routes, or time of travel) will assure a safe movement.

iii. The damage inspection process outlined above will help determine what safeguards are necessary for the safe cask retrieval and Toading onto another transport vehicle provided by Tri-State.

\section{f. Structural Assessment}

i. Under severe accident conditions it is possible that the cask, cask and skid, or even the trailer with cask/skid attached will not be in normal orientation, and will require relocation to a preferable orientation for further work.

ii. A structural assessment may be requested by WHC and DOE to identify components, and the connection of components, that are sufficiently intact to accommodate the forces imposed during initial relocation operations.

iii. Their assessment will include examination of the structural capacity of wreckage constituents that must be removed prior to movement of the cask. Failure of these components during handling could have a negative influence on the cask and contents. 


\section{WHC - MR - 0523, KEV.O \\ CESIUM TRANSPORTATION PLAN Rev. 0 June 1996}

iv. Another part of a possible structural assessment is the identification of possible remedies that might improve the loadbearing capacity of components that are necessary for recovery purposes. For instance, rewelding a broken skid member, replacing a damaged trunnion, or installing a reinforcing brace on the trailer may provide the strength necessary for safe handling.

\section{g. Recovery Operations}

Specific recovery actions must be formulated for the conditions that prevail at the accident scene. For the BUSS cask and transportation system there are some general guidelines and recommendations that may be useful in the formulation of specific recovery actions.

\section{General Guidelines:}

j. If the connections between the trailer and skid and between the skid and cask are secure, the trailer may be grappled and used to pull the other components if relocation is required. Neither the cask nor the skid should be grappled and used to pull the trailer since the size and weight of the trailer could exert excessive force on the cask or skid.

ii. If the cask and trailer are significantly disrupted, it is recommended that the trailer be separated from the cask/skid. Separation shall occur by removing the connecting bolts or by component cutting. Other wreckage should be removed prior to working on the cask and transporter.

iij. If separated from the trailer, the skid may be grappled to move the skid/cask assembly for relocation. Acceptable grappling points on the skid are the structural steel base components. Do not grapple the turnbuckle assemblies that connect the cask to the skid. Grapple point connections (e.g., brackets) may be welded on to the carbon steel base components if necessary.

iv. The cask may be grappled and moved with the skid attached as long as the grappling points are appropriate. Acceptable grappling points on the cask are: one or both of the trunnions and one or both of the horizontal lifting points on the upper centerline. Cables or slings may be passed around the cask body to form a noose or choker. Cables may nest in between cooling fins. Do not attach any grapple to the 1 id or vent/drain penetrations or to the turnbuckles or impact limiter hardware. As a last resort, welding attachment brackets on the stainless steel cask body is acceptable provided there is not significant disruption of heat displacement capability. Weld and welder qualification is required as is weld inspection prior to use.

v. The conventional lifting devices should be used in the recovery effort if the cask orientation and conditions permit and the attachment points have been viewed as acceptable. Replacement brackets/trunnions and fasteners are recommended if damage has been observed. 
WHC-MK-0523, IEH.

CESIUM TRANSPORTATION F'LAN Rev. 0 June 1996

vi. Lid and penetration bolt tightening should be attempted if the damage is such that they are accessible. Judgment must be exercised regarding the replacement of damaged bolts. If lid bolt damage seems extensive and replacement is difficult, consideration should be given to welding retaining straps across the lid or welding clips around the lid periphery to act as mechanical stops. These measures can provide lid retention but cannot assure lid sealing.

vii. If the cask body is generally undamaged, it may be possible to equip it with replacement limiters and ship it on another skid and trailer.

viii. If the impact limiters and skid are significantly damaged, consideration should be given to removing them prior to transport. This can only be sanctioned by DOE. The cask body may be placed on a suitable trailer and blocked and secured appropriately. The previously-identified cask body attachment points may be used as part of the transport tiedown arrangement. Horizontal orientation is preferred for heat transfer purposes.

ix. If the skid is unusable, but the impact limiters are reasonably functional, the limiters should be retained for transport protection and the body blocked or shored in the horizontal position on a trailer deck. The limiters must not bear any of the weight of the cask. Cask tiedown can be by cables, chains, etc.

$x$. Wrapping the cask for transport should be considered only after determining that the heat displacement will be unaffected. The BUSS cask has a design basis heat load of $4 \mathrm{~kW}$.

h. Recovery Resource Determination

i. After assessing the cask damage and the condition of the accident scene, the specific recovery resources can be identified (see Attachment B).

ii. Experienced rigging companies are identified in Attachment B. These companies have equipment for welding, cutting, etc., in support of recovery operations. 
ATTACHMENT A: EMERGENCY RESPONSE KIT INVENTORIES AND INSPECTION CHECK SHEET

\begin{tabular}{|c|c|c|}
\hline QUANTITYITTEM & SAT/UNSAT & INITIALSIDATE \\
\hline \multicolumn{3}{|l|}{ (1) High Range Rad Inst. } \\
\hline \multicolumn{3}{|l|}{ (1) Low Range Rad Inst. } \\
\hline \multicolumn{3}{|l|}{ (1) Contamination Inst. } \\
\hline \multicolumn{3}{|c|}{ (2) Spare Cords/(1) Portable Radio Charger } \\
\hline \multicolumn{3}{|l|}{ (1) Check Source } \\
\hline \multicolumn{3}{|c|}{$\begin{array}{l}\text { 1100) Smear Papers } /(20) \text { High Volume Air } \\
\text { Sample Filters }\end{array}$} \\
\hline \multicolumn{3}{|l|}{ (2) Sets Sparo Batteries } \\
\hline \multicolumn{3}{|l|}{ \{50 ft\} Bartier Rope } \\
\hline \multicolumn{3}{|l|}{ (4) Warning Signs/inserts } \\
\hline \multicolumn{3}{|c|}{ (2) Flashlights/(1) High Volume Air Samplor } \\
\hline \multicolumn{3}{|l|}{ (20) Survey Forms } \\
\hline \multicolumn{3}{|l|}{ (10) Blank Rad. Tags } \\
\hline \multicolumn{3}{|l|}{ Box of Pens } \\
\hline \multicolumn{3}{|l|}{ (10) Pairs of Tyveks } \\
\hline \multicolumn{3}{|l|}{ [1] Box Surgeons Gloves } \\
\hline \multicolumn{3}{|l|}{ L.arge Plastic Bags } \\
\hline \multicolumn{3}{|l|}{$\begin{array}{l}\text { 11) Miero-Cassette Recorder } \\
\text { (4) Blank tapes }\end{array}$} \\
\hline \multicolumn{3}{|l|}{ (1) Calculator } \\
\hline \multicolumn{3}{|l|}{ (1) 200 Page Logbook } \\
\hline \multicolumn{3}{|l|}{ (5) Rolls Duct Tape } \\
\hline \multicolumn{3}{|l|}{ (2) Pair Safety Glasses } \\
\hline \multicolumn{3}{|l|}{ (2) Orange Vests } \\
\hline \multicolumn{3}{|l|}{ (4) Pair Leather Gloves } \\
\hline \multicolumn{3}{|l|}{ (1) Box Gallon zip tock bags } \\
\hline \multicolumn{3}{|l|}{ (t) Box Blank Stickers } \\
\hline \multicolumn{3}{|l|}{ (3) Black Markers } \\
\hline \multicolumn{3}{|l|}{ (3) Cans Orange Spray Paint } \\
\hline \multicolumn{3}{|l|}{ (1) Camera (2) rolls of Film } \\
\hline \multicolumn{3}{|l|}{ (10) TLD Badges } \\
\hline (10) Pocket Dosimeters & & \\
\hline (50) Brieting Sheets & & \\
\hline (2') CB Radios/(3) Hand-Held Radio & & \\
\hline (2) Clipboards & & \\
\hline Copy of Transportation Plan & & \\
\hline Copv of OHM Health \& Safety Mtan & & \\
\hline Copy of H\&S Plan/29 CFR/49 CFR & & \\
\hline
\end{tabular}


WHC-MK-0SW

CESIUM TRANSPORTATION PLAN Rev. 0 June 1996

Supplementary Instructions for Inventory

1. Radiation detection instruments must be operationally checked, including, a physical check, a battery check, and a source check. The radiation source contained in the kit is suitable to perform these checks. Both spare cords shall be installed and checked.

2. The cassette recorder shall be checked by recording and replaying a voice message.

3. The calculator shall be checked by powering up and performing severa? calculations.

4. The spare batteries shall be checked for the expiration date.

5. The $C B$ radios shall be powered up and checked by communicating between the two radios.

6. The camera battery shail be checked. The expiration date for the $f i 7 m$ shall be checked.

7. The flashlights shall be checked. 
$\omega H C-m R-0523, t E V .0$

CESIUM TRANSPORTATION PLAN Rev. 0 June 1996

\section{ATTACHMENT B: \\ ANDERBERG COMMUNICATIONS \\ EMERGENCY NOTIFICATION CHECK SHEET \\ ANDERBERG COMMUNICATIONS \\ EMERGENCY NOTIFICATION CHECK SHEET \\ for}

OHM REMEDIATION SERVICES CORP. EMERGENCY RESPONSE NOTIFICATIONS

1. Name of the person reporting the incident:

DATE

TIME

2. Nature or type of incident:

3. Location of the scene, highway number, north or southbound lane, mile marker, nearest town or city:

4. Description of the Scene:

Is there?

A fire:

A fuel spiाT:

Injuries:

Number of vehicles Involved:

Have local authorities arrived at the scene:

Other notifications made:

5. Cellular Phone or Fixed Phone Number for person reporting the incident:

Advise the person that the Emergency team members will be calling back for more details and to remain available. 
WHC-MK-0523, NEV.C

CESIUM TRANSPORTATION PLAN Rev. 0 June 1996

After this information is obtained, terminate the call and make notifications to the OHM Emergency Response Team as follows:

1. Dial 1-800-796-7363. This number activates the pagers carried by team members.

2. Perform a global activation of Response Team Member Pagers by dialing the following PIN \#:

$\begin{array}{lr}\text { Alpha Numeric PIN } \# 555-5861 \\ \text { Digital PIN \# } & 106-3586\end{array}$

If Emergency Response is requested send the following Alpha Numeric message:

"Emergency Response requested at date/time. Contact Anderberg Communications at 1-800-925-4959."

3. In addition to global PIN numbers, each individual pager has separate alpha numeric and digital PIN numbers. The following is a list of the national wide individual PIN numbers:

$\begin{array}{lcc}\text { Personnel } & \text { Alpha Numeric PIN \# } & \text { Digital PIN \# } \\ & & \\ \text { Jeff Stevens } & 555-1387 & 105-9575 \\ \text { Steven McQueary } & 555-5131 & 105-9573 \\ \text { Walter Paulson } & 555-1533 & 105-9574 \\ \text { Wayne Gaul } & 555-2085 & 105-9577\end{array}$

2. If after 15 minutes none of the team members have called in, call the following home phone numbers:

$\begin{array}{ll}\text { Jeff Stevens } & (303) 644-3350 \\ \text { Steven McQueary } & (303) 644-3621 \\ \text { Walter Paulson } & (803) 779-1696 \\ \text { Wayne Gaul } & (803) 732-8522\end{array}$

3. If no contact can be made, call the OHM Denver Office at: (303) 371-8252. If a response is not received at the Denver, CO office, cail the Columbia, SC office at: (803) 256-1555.

When the team members call in, provide all the emergency information collected from the person at the scene. Inform each team member of the other members that have checked in and where they are en route to.

Be prepared to act as an information collection and distribution station in the event that other types of communications fail between Emergency Team members and persons at the scene. 
WHe - MR - OS23, KEV

CESIUM TRANSPORTATION PLAN FEV, O June 1996

\section{ATTACHMENT C \\ QUALIFIED VENDORS LIST}

SHOP

Richmond, VA

Peterbilt of Richmond, Inc.

2800 Deep water Terminal Rd.

(804) 231-9800

Charleston, WV

Goodyear Tires

$2907 \mathrm{~W}$. 4th

(304) 744-9474

Copley CC Spike, Inc.

1009 Centra1 Ave.

(304) 346-0338

Mountain International

Crosslanes I-64 Exit 42

(304) 776-5600

Louisvi1le, KY

$A B C$ Tire

4134 Reservoir Ave.

(502) 452-1998

Coffey's Wrecker Service

4594 Poplar Level Rd.

(502) 968-3377

Indianapolis, IN

Utility/Peterbi?t

$4255 \mathrm{~S}$. Harding St.

(317) 788-0299

Goodyear Truck Tire Center

6315 Brookville Rd.

(317) 353-0696

Hix Wrecker Service

3200 Bluff Dr.

(317) 783-3111

8loomington, IL

McLean County Truck Veterans Parkway \& Mercer Ave.
24 Hours

TYPE OF SERVICE

24 Hours

Shop

24 Hours

Tires

Wrecker

Shop

24 Hours

Tires

24 Hours

Wrecker

24 Hours

Shop

24 Hours

Tires

24 Hours

Wrecker

Shop (309) 662-1331 
WHC-MK.0523, IEH

CESIUM TRANSPORTATION PLAN Rev. 0 June 1996

SHOP

Peoria, IL

Rocket Tire Service

300 Edmond

(309) 676-0124

Tazwell Towing

727 N. Main

(309) 699-9728

Des Moines, IA

Hanien Company

5328 2nd Ave.

(515) 243-3205

Goodyear Commercial Tire and Service

1976 N.E. Broadway

(515) 265-2509

Grand Island, NE

Nebraska Peterbilt

8225 S. U.S. 281

(308) 382-1044

Garrett G\&S Tire Center

3004 01d Pothah Hwy.

(308) 382-0809

Cheyenne, WY

Western IH

701 E. 1st St.

(307) 635-4221

Able Al Towing

2813 S. Greeley Hwy.

(307) 638-8883

Laramie, WY

A to $Z$ Tire

(307) 742-8241

Clay's Towing and Service

Curtis and $I-80$

(307) 745-8316

Rawl ins, WY

Wyoming Diesel Service

2305 DaTey

(307) 324-5144
HOURS OF SERVICE

24 Hours

Tires

24 Hours

Wrecker

24 Hours

Wrecker

24 Hours

Shop

24 Hours

Shop

24 Hours

Tires and Wrecker

$7: 30-$ Midnight M-F

Shop

8:00-4:00 Sat

On Cal1 24 Hours

24 Hours

wrecker

$7: 30-5: 30 \quad M-F$

Shop

Tires

24 Hour Tow

wrecker

8-6 M-F

Shop 
SHOP

Rip Griffins Truck Service 201 E. Spruce (307) 324-4113

Roadrunner Emergency Repair 201 E. Spruce (307) 324-4113

Terry's Towing 1924 W. Spruce (307) 324-9331

\section{Wamsutter, WY}

McDowell Enterprises

Exit $175 \quad 1-80$

(307) 324-7818

Rock Spring, WY

The Tire Den

212 Industrial Dr. (307) 382-4700

Smith DDA

20 Bowler Rd. (307) 382-4330

L.JD Towing

250 Summit

(307) 382-4553

Cummins Intermountain

2000 Foothill Bivd

(307) 362-5168

Litt]e America

I-80 Exit 68

(307) $875-2400$

Lyman, WY

kross Kountry Truck

Towing and Repair

215 E. Clark

(307) 787-6743

Evanston, WY

Wyoming Transport Tire 80 A l legiance Rd.

(307) 789-5040

Jim's Diesel Towing

1443 U.S. Hwy 30 E. I -80

(307) 789-3825
HOURS OF SERVICE

24 Hours

TYPE OF SERVICE

Shop and Tires

24 Hours

Shop

24 Hour Tow

Wrecker

No Nat'1 Accts

Tires and Shop

$\mathrm{B} / \mathrm{S}$

24 Hour Road Service

24 Hour Road Service

Shop Hours 8:00-5:00 M-F

24 Hour Road Service

Shop Repair

24 Hour Road Service

Shop. Repair

24 Hour B/S Tires

24 Hour Shop

Tires

Shop

Wrecker and Shop

$B / S$

24 Hour Road Service

Tires

24 Hour Towing

Wrecker 


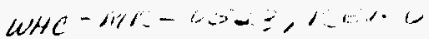

CESIUM TZANSPORTATION PIAAN Rev. O JunE 1996

SHOP

Frenchie's Diesel Truck Rep

53 Enterprise Lane (307) 789-7247

HMH

402 Duncumb Hollow Dr.

(307) $789-1356$

Mobile \#(307) 789-1193 or 1111

ogden, UT

Stauffer's Skyhook

Towing \& Repair

3707 th St.

(801) 399-5893

Flying $J$

2096 S 1100 West

(801) 621-7575

JW Brewer Tire Company

1690 Wall Ave.

(801) 393-8641

Ogden Diesel

$1212 \mathrm{~W}$. Wilson

(801) $394-7130$

(801) 295-7005

Tremonton, UT

Archibald \& Sons Husky Service 979 W. Main

(801) 257-3327

Hathaway's Towing

148 S. 1600 East

(801) 257-5084

Rupert, ID

Jack's Towing Service

(208) 436-4034

Burley, ID

Gem International

1106 Hansen Ave

(208) 678-9057

Ca11 out \# Ross (208) 678-3004

Wayne (208) 678-8506

Larry (208) 678-0987

Steve (208) 522-4105

National Navistar
HOURS OF SERVICE

$8: 00-4: 30$ M-F

TYPE OF SERVICE

Shop

24 Hour Road Service and Shop

Shop

24 Hour Towing

Wrecker

B/S Tires

7:00-11:00 PM

Tires

B/S Yokohama

24 Hour Road Service

Tires

8:00-4:30 PM

Mike Warr

Shop

24 Hour Road Service

Goodyear Nationa?

Minor Truck Repairs

24 Hour Towing

Wrecker

24 Hour Towing

Wrecker

24 Hour Towing

Road Service \& Repairs

Wrecker

Shop 
WMC-MK-OS2 $3, K C V . O$

CESIUM TRANSPORTATION PIAN Rev. 0 June 1996

SHOP

Commercial Tire

2030 Kimberly Rd.

(208) 733-8761

After Hours (208) 733-8761

Magic Valley Towing

Kimberly Road \& 3200 East

(208) 734-6138

Magic Valley IH

259 4th Ave. West

(208) 733-4266

Jerome, ID

Trebar Kenworth

300 Road South

(208) 324-8886

Gooding, ID

Commercial Tire

621 S. Main

(208) 934-5614

After Hours (208) 934-8580

Jim's Repajr

280 E. Roosevelt

(208) 934-4341

After Hours (208) 934-4016

Mountain Home, ID

Leo's Towing Service

(208) 587-4690

Ray's Mobile Service

(208) 587-6313

Pager \#(208) 587-1125

EXT 1575-1574

Boise, ID

Commercial Tire

1950 S. Cole Rd.

(208) 322-4177

After Hours Answering Service

(208) 377-3400

$B$ \& W Towing

$20 \mathrm{~S}$. Garden

(208) 342-254]

Lake City IH

770 W. Amity Rd.

(208) $345-6410$
HOURS OF SERVICE

24 Hour Road Service

B/S GN Tires

24 Hour Tow

Minor Repairs

8:00-5:00 M-Sat

24 Hour Call Out

Shop

$7: 30-1: 00$ AM M-F

8:00-5:00 Sat \& Sun

Road Service

B/S General

24 Hour Road Service

Tires

24 Hour Road Service

Shop

24 Hour Towing

Wrecker

24 Hour Road Service

Shop

24 Hour Road Service

Tires

24 Hour Towing

Wrecker

24 Hours M-F

$7: 30-5: 30$ Sat \& Sun

Shop

Tires

Shop

Wrecker

s

F SERVICE 
WHC-MK-0.523, MEV.

CESIUM TRANSPORTATION PLAN Rev. 0 June 1996

SHOP

Ontario, OR

Ontario Diese 1

$588 \mathrm{~S}$. E. lst Ave

(541) 889-8681

Commercial Tire

$273 \mathrm{E}$. Idaho Ave.

(503) 889-6714

After Hours (503) 889-6714

Baker, OR

Baker Valley Towing

85 David Eccles Rd.

(503) $52 \cdot 3-2154$

Roy \& Owen's Tire Service

2122 loth Place

(503) 523-6401

Nights (503) 523-6668

La Grande, OR

Commercial Tire

911 Jefferson

(541) 963-2887

After Hours (541) 963-3540 or

(541) 963-3291

Eagle Truck \& Machine

26 th and Hiwy 82

(541) 963-8551

Fenn's Wrecker Service

60376 Bushnel1 Rd.

(503) 963-6050

Pendleton, OR

Woodpecker Truck \& Equip.

I-84 Exit 202

(503) 276-5515

Umatilla, 0R

2 Brothers Truck Repair

Behind Crossroads Truck Stop (503) 922-3439

or Call (503) 567-1451
HOURS OF SERVICE

TYPE OF SERVICE

8:00-5:00 M-F

$8: 00-4: 30$ Sat

24 Hour Road Service

Tires

24 Hour Towing

Wrecker

24 hour Road Service

Tires

24 Hour Road Service

Tires

24 Hour Road Service 8:00-11:00 PM M-F

24 Hour Towing

Wrecker

7:00-9:00 PM M-F

Wrecker-Road Service

Wrecker

Shop

24 Hour Road Service

Shop 


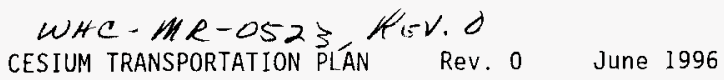

\section{ATTACHMENT D: QUALIFIED CRANE AND LIFTING RESOURCES}

Ashl and, VA

Reebals, Inc.

114 Qual Rd.

24 hour phone (804) 798-8616

Louisville, $\mathrm{KY}$

AMCO Bramer

4314 Can Run Rd.

24 hour phone (502) 447-2472

Lincoln, NE

Davis Crane and Erection

$100 \mathrm{P}$

24 hour phone (402) 438-7949

Omaha, NE

Davis Crane and Erection

5910 S. 27 th

(402) 731-7484

Salt Lake City, UT

Acme Crane Rental

P. 0. Box 65374

Salt Lake City, UT 84165

24 hour phone (801) 466-7902

Kennewick, WA

Nej1 F. Lampson

P. 0. Box 6510

Kennewick, WA 99336

24 hour phone (509) 586-0411

40-140 ton truck cranes available
St. ATbans, WV

All Crane

6540 MacCorkle

24 hour phone (304) 766-0300

St. Louis, MO

Budrovich Contracting $\mathrm{CO}$.

2529 Lemay Rd.

24 hour phone(800) 886-8923

North Platte, NE

Simon Construction

800 Lake Dr.

As Available phone (308) 532-8600

Cheyenne, WY

Certified Welding Corporation

P. 0. Box 954

Cheyenne, WY 82001

(307) $632-4350$

24 hour phone (307) 634-2371

40-140 ton truck cranes available

Boise, ID

Record Steel and Construction

Company

250 North Locuse Grove Road

Meridian, ID 83642

24 hour phone (208) 887-1401

40-140 ton truck cranes available 
WHC- A

CESIUM TRANSPORTATION IAN Rev. 0 June 1996

This page intentionally left blank. 


$$
\text { WHC- } M \text { H - OS23, KEV. } 0
$$

CESIUM TRANSPORTATION PLAN Rev. 0 June 1996

APPENDIX C: GUIDE 1641996 EMERGENCY RESPONSE GUIDEBOOK 


$$
\text { WHAC-MA-CDar, rEW.O }
$$

CESIUM TRANSPORTAT ON PLAN Rev. 0 June 1996

\begin{tabular}{|c|c|}
\hline & $\begin{array}{l}\text { RADIOACTIVE MATERIALS (SPECIAL FORM/ } \\
\text { LOW TO HIGH LEVEL RADIATION) }\end{array}$ \\
\hline \multicolumn{2}{|r|}{ POTENTIAL HAZARDS } \\
\hline \multicolumn{2}{|c|}{ 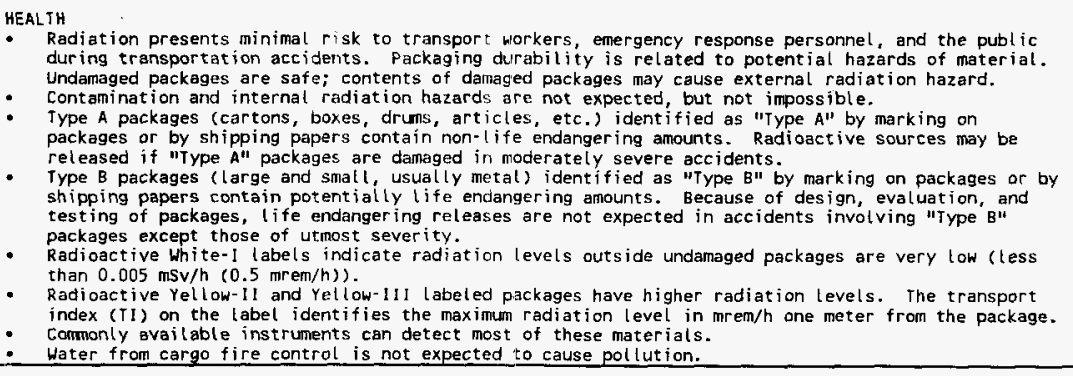 } \\
\hline \multicolumn{2}{|c|}{$\begin{array}{l}\text { FIRE OR EXPLOSION } \\
\text { Packagings can burn completely without risk of content loss from sealed source capsule. } \\
\text { Radioactivity does not change flamability or other properties of materials. } \\
\text { Radioactive source capsules and Type B packages are designed and evaluated to withstand total } \\
\text { engulfment in flames at temperatures of } 800^{\circ} \mathrm{C}\left(1475^{\circ} \mathrm{F}\right) \text {. }\end{array}$} \\
\hline \multicolumn{2}{|r|}{ PUBLIC SAFETY } \\
\hline $\begin{array}{l}\text { CaLl } \\
\text { or } r \\
\text { Prio } \\
\text { the } \\
\text { Radi } \\
\text { radi } \\
\text { Isol } \\
\text { dire } \\
\text { Stay } \\
\text { Keep } \\
\text { Dela }\end{array}$ & $\begin{array}{l}\text { gency Response Ielephone Number on Shipping Paper first. If Shipping Paper not avaitable } \\
\text { wer, refer to appropriate telephone number listed on the inside back cover. } \\
\text { is for rescue, life-saving, first aid, and control of fire and other hazards are higher than } \\
\text { ity for measuring radiation levels. } \\
\text { Authority must be notified of accident conditions, and is usually responsible for } \\
\text { cal decisions. } \\
\text { pill or leak area immediately for at least } 25 \text { to } 50 \text { meters ( } 80 \text { to } 160 \text { feet) in all } \\
\text { s. } \\
\text { nd. } \\
\text { thorized personnel away. } \\
\text { al cleanup until instructions or advice is received from Radiation Authority. }\end{array}$ \\
\hline \multicolumn{2}{|c|}{$\begin{array}{l}\text { PROTECTIVE CLOTHING } \\
\text { POSitive pressure self-contained breathing apparatus (SCBA) and structural firefighters' protective } \\
\text { clothing will provide adequate protection against internal radiation exposure, but not externat } \\
\text { radiation exposure. }\end{array}$} \\
\hline $\begin{array}{l}\text { Evacua } \\
\text { Large } \\
\text { Fire } \\
\text { Wh } \\
\text { di }\end{array}$ & a major fire, consider an initial eva \\
\hline
\end{tabular}


$W H C-m K-0.523, N V . c$

CESIUM TRANSPORTATION PLAN Rev. O June 1996

\begin{tabular}{|c|c|c|}
\hline $\begin{array}{l}\text { GUIDE } \\
164\end{array}$ & $\begin{array}{l}\text { RADIOACTIVE MATERIALS (SPECIAL FORM/ } \\
\text { LOW TO HIGH LEVEL RADIATION) }\end{array}$ & NAERG96 \\
\hline \multicolumn{3}{|c|}{ EMERGENCY RESPONSE } \\
\hline \multicolumn{3}{|c|}{$\begin{array}{l}\text { FIRE } \\
" \text { Presence of radioactive material will not change effectiveness of fire control techniques. } \\
\text { Move containers from fire area if you can do it without risk. } \\
\text { Do not move damaged packages; move undamaged packages out of fire zone. } \\
\text { Small Fires } \\
\text { Large fires } \\
\text { Lateal, } \mathrm{CO}_{2} \text {, water spray or regular foam. } \\
\text { Water spray, fog (flooding arnounts). }\end{array}$} \\
\hline \multicolumn{3}{|c|}{$\begin{array}{l}\text { SPILL OR LEAK } \\
\text { " Do not touch damaged packages or spilled material. } \\
\text { Stightly damaged or damp outer surfaces seldom indicate faiture of packaging since most have an } \\
\text { inner container. } \\
\text { If source is identified as being out of package; stay away and await advice from Radiation } \\
\text { Authority. }\end{array}$} \\
\hline \multicolumn{3}{|c|}{$\begin{array}{l}\text { FIRST AID } \\
\text { " Medical problems take priority over radiological concerns. } \\
\text { Use first aid treatment according to the nature of the injury. } \\
\text { Do not delay care and transport of a seriously injured person. } \\
\text { " Persons exposed to special form sources are not likely to be contaninated with radioactive material. } \\
\text { "Apply artificial respiration if victial is not breathing. } \\
\text { Administer oxygen if breathing is difficult. } \\
\text { Injured persons who contacted released material may be a minor contamination problem to contacted } \\
\text { persons, equipment and facilities. }\end{array}$} \\
\hline
\end{tabular}


$w H e-r_{1} k-\omega_{0}=, \mu \in V . O$

CESIUM TRAASPORTAT:ON PLAN Rev, 0 June 1996

This page intentionally left blank. 
CESIUM TRANSPORTATION PLAN Rev. 0 June 1996

APPENDIX D: LYNCHBURG, VA-HANFORD, WA HRCQ ROUTE MAP 
WHC- WH-052, , E H

CESIUM TRANSPORTATION FLAA Rev. 0 June 1996
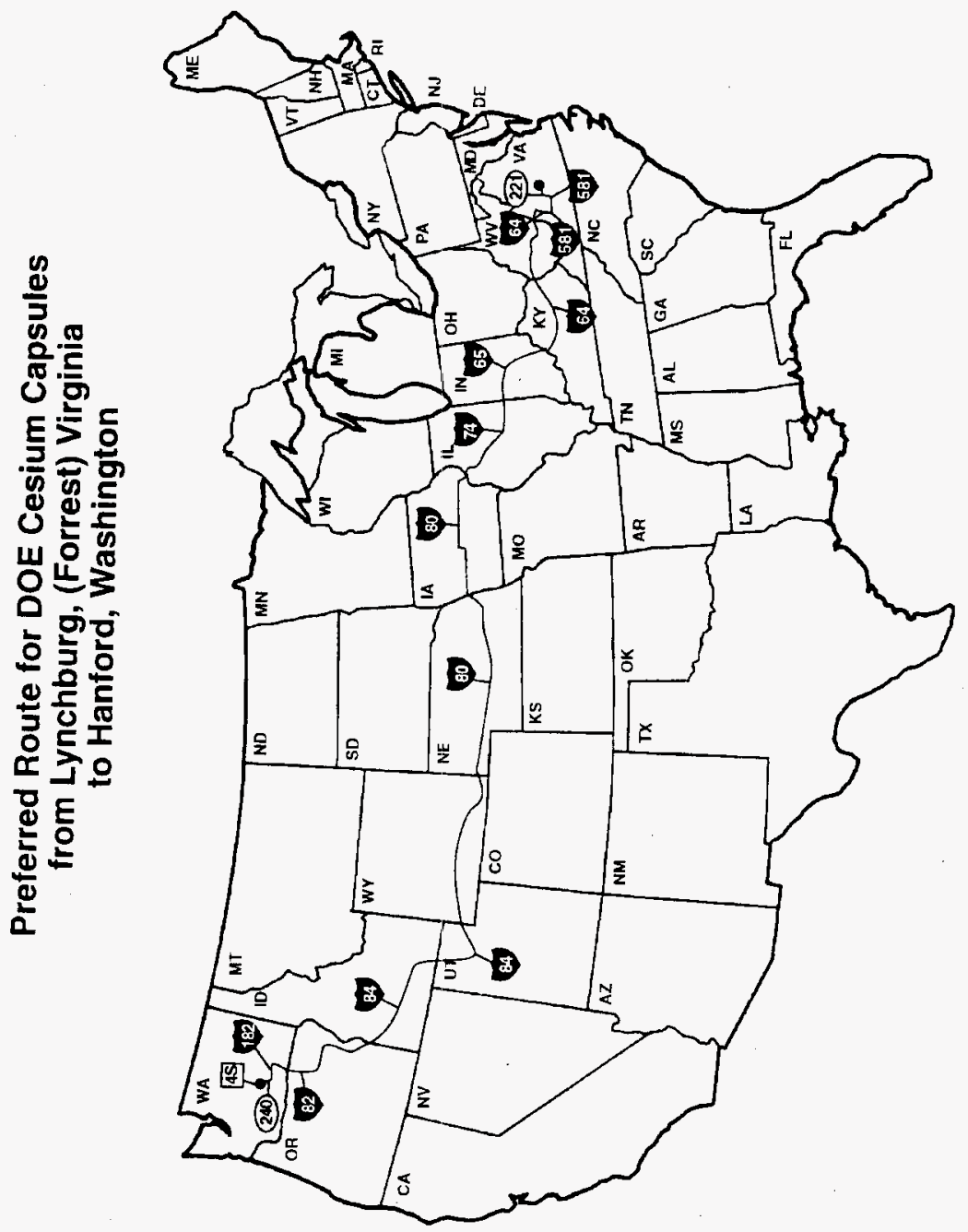
WHC - MR- $0523, T E V . O$

CESIUM TRANSPORTATION PLAN ReV. 0 June 1996

APPENDIX E: STATE/CONFEDERATE TRIBES OF THE UMATILLA INDIAN RESERVATIONS (CTUIR) CONTACTS FOR EMERGENCY CONDITIONS 
$\omega H C-r i t-c \cdots=-\infty, \cdots 1=1$

CESIUM TRAISPORTATION PLAN REY. 0 June 1996

\begin{tabular}{|c|c|c|}
\hline State/Tribe & Contact & Phone \\
\hline Virginia & $\begin{array}{l}\text { Virginia State Police Duty } \\
\text { Sergeant }\end{array}$ & (804) $674-2026$ \\
\hline West Virginia & West Virginia State Police & $(304) \quad 746-2158$ \\
\hline Kentucky & $\begin{array}{l}\text { Department of Emergency } \\
\text { Services (DES)-Operations State } \\
\text { Police Ashland Post }\end{array}$ & $\begin{array}{l}(502) 564-7815 \\
(606) \quad 928-6421 \\
\end{array}$ \\
\hline Indiana & $\begin{array}{l}\text { Indiana State Emergency } \\
\text { Management Agency (SEMA) }\end{array}$ & $(800) \quad 669-7362$ \\
\hline Illinois & $\begin{array}{l}\text { IDNS REAC 24-hour } \\
\text { Communications Center } \\
\text { Illinois State Police } \\
\text { Communications Center } \\
\text { Illinois Emergency Mgmt }\end{array}$ & $\begin{array}{l}(217) 785-0600 \\
(217) 786-6677 \\
(217) 782-7860 \\
\end{array}$ \\
\hline Iowa & Emergency Management Division & (515) $281-3231$ \\
\hline Nebraska & Nebraska State Patrol (24 hr) & $(402) \quad 471-4545$ \\
\hline Wyoming & $\begin{array}{l}\text { Wyoming Highway Patrol Dispatch } \\
\text { Center }\end{array}$ & $(307) 777-4321$ \\
\hline Utah & $\begin{array}{l}\text { Utah Highway Patrol Dispatch } \\
\text { Center }\end{array}$ & (801) $965-4505$ \\
\hline Idaho & $\begin{array}{l}\text { Idaho State Police } \\
\text { Boise Dispatch Center } \\
\end{array}$ & (208) $334-2900$ \\
\hline Oregon & Oregon State Patro] & $(503) \quad 378-2575$ \\
\hline Washington & Washington State Patrol & (509) 575-2323 \\
\hline $\begin{array}{l}\text { Confederated Tribes of the } \\
\text { Umatilla Indian Reservation }\end{array}$ & Tribal Police and Fire Dispatch & $(503) 278-0550$ \\
\hline
\end{tabular}


WHC-MR-0523, 1 EV. 0

CESIUM TRANSPORTATION PLAN Rev. 0 June 1996

APPENDIX F: STATE/CTUIR SUMMER SEASON/ROAD CONDITIONS POLICY 
WHC- $M K-\cos 3, \quad K E \% \cdot C$

CESIUM TRANSDORTATION PLAN Rev. 0 June 1996

\subsection{INTRODUCTION}

Summer season inclement weather and bad road conditions can create hazardous travel. The safety of the public and the need to ensure public confidence in this shipping program require that reasonable measures be taken to prevent traffic accidents that can be avoided through common sense precautions. The purpose of this document is to establish the policy for the safe parking criteria for the ${ }^{137}$ C.s shipments. TRANSCOM will be used to track the ${ }^{137} \mathrm{Cs}$ shipments. Vehicles will be equipped with communication systems that will allow consultation between the driver and TCC at all times. States and the CTUIR along the route can use TRANSCOM to track the location of shipments as they pass through each jurisdiction. These capabilities provide a unique opportunity for the states, CTUIR, and DOE to work together to reduce the risk that these two shipments may be involved in a transportation. incident. DOE/WHC has established that current Cs transport from the ARECO facility will occur during the summer season (May 1 - September 30) as specified in Section 3.5 of this document.

\subsection{CRITERIA FOR DISPATCHING SHIPMENTS}

Before dispatch, DOE, through WHC, will have advanced weather and driving conditions checked by the TCC staff using the WSI Weather for Windows Service. It is the states'/tribes' responsibility to notify the TCC if weather or road conditions are expected to be unacceptable during the projected shipment period through that state/tribal corridor.

\subsection{EVALUATION CRITERIA}

- Monitoring The Weather Channel in the TCC

- Output from weather information software (WSI)

- Carrier

- State Contacts (e.g., State Highway Patrol or Police)

If additional information is needed, State Highway Patrol, State Police, or other state-designated agencies should be contacted. Contacts for each state are listed in Table 1. For CTUIR, Oregon will serve as the contact. 


\subsection{DISPATCH PROCEDURES}

As a minimum standard, the local weather conditions, the weather forecast, and current road conditions as determined by the state/tribal designate must be acceptable before a shipment enters its corridor. If WHC, the carrier, a state, or CTUIR determines that weather or road conditions are not acceptable prior to leaving or entering its jurisdiction under the above criteria, WHC will not dispatch a shipment into that state/tribal corridor until weather/road conditions improve and the designated state/tribal authority has granted permission to enter and proceed through its controlled corridor. Before the decision to dispatch a shipment from the ARECO facility, the TCC will evaluate the weather and road conditions by monitoring the sources 1isted in Appendix F, Section 2.0. It is the states'/tribes' responsibility to notify the TCC if weather/road conditions are expected to be unacceptable during the projected shipment period through the state/tribal corridor. TCC will provide WHC with current weather, road conditions, and state/tribal information if safe parking is required. TCC will provide the same information for dispatching and holding a shipment in a designated safeparking area until conditions improve in that particular stretch of affected transportation corridor. 


\section{WHC-MK-OS23, KEV.O \\ CESIUM TRANSPORTATION PLAN Rev. 0 June 1996}

Table 2. State and CTUIR Contacts.'

\begin{tabular}{|c|c|c|}
\hline State & Contact & Phone \\
\hline Virginia & Virginia State Police Duty Sergeant & (804) $674-2026$ \\
\hline West Virginia & West Virginia State Police & (304) $746-2158$ \\
\hline Kentucky & $\begin{array}{l}\text { DES-Operations } \\
\text { State Police Ashland Post }\end{array}$ & $\begin{array}{c}(502) \quad 564-7815 \\
(606) \\
\end{array}$ \\
\hline Indiana & $\begin{array}{l}\text { State Emergency Management Agency } \\
\text { (SEMA) Dispatch Center }\end{array}$ & $(800) 669-7362$ \\
\hline Illinois & $\begin{array}{l}\text { Illinois DOT Weather and Road Hazards } \\
\text { Illinois DOT Construction Information }\end{array}$ & $\begin{array}{l}(800) 452-4368 \\
(217) 782-2937 \\
\end{array}$ \\
\hline Iowa & $\begin{array}{l}\text { State Road and Travel Information } \\
\text { Service (taped message) } \\
\text { Iowa DOT/Motor Vehicle Division }\end{array}$ & $\begin{array}{l}(515) \quad 288-1047 \\
(515) \quad 237-3106 \\
\end{array}$ \\
\hline Nebraska & Nebraska State Police & (402) $471-4545$ \\
\hline Wyoming & Wyoming Highway Patrol Dispatch Center & (307) $777-4321$ \\
\hline Utah & Utah Highway Patrol Dispatch Center & (801) $965-4505$ \\
\hline Idaho & $\begin{array}{l}\text { Idaho State Police Boise Dispatch } \\
\text { Center }\end{array}$ & (208) $334-2900$ \\
\hline oregon $^{2}$ & Oregon Emergency Response System & (503) 378-6377 \\
\hline Washington & $\begin{array}{l}\text { Washington State Patrol Yakima } \\
\text { District Headquarters }\end{array}$ & (509) $575-2323$ \\
\hline
\end{tabular}

\subsection{STATE AND CTUIR PROCEDURES}

State and tribal authority should monitor the status of Cs shipments using the TRANSCOM system when adverse weather and road conditions are being experienced. If a $C_{S}$ shipment is listed on TRANSCOM with a departure time that would cause the shipment to encounter adverse conditions when entering the effected state or tribal corridor, the state or tribal designate should notify the TCC at (423) 576-9115 of the need to delay entry into that particular effected transportation corridor due to adverse conditions. Additional points of contact include WHC and the carrier. Contact telephone numbers are 1 isted in Table 3 . 
WHC-MR-0523, REV. O

CESIUM TRANSPORTATION PLAN Rev. 0 June 1996

Table 2. Contacts for Cs Shipments.

\begin{tabular}{|l|c|}
\hline \multicolumn{1}{|c|}{ Contact } & Phone \\
\hline TCC & (423) $576-9115$ \\
\hline WHC & (509) $373-3800$ \\
\hline TSMT (Safety Department) & (800) 723-8768 \\
\hline
\end{tabular}

${ }^{1}$ TCC is the primary contact. other contacts are listed in order of priority.

\subsection{ADVERSE CONDITIONS EN ROUTE}

"Extreme caution in the operation of a motor vehicle shall be exercised when hazardous conditions such as those caused by snow, ice, sleet, fog, mist, rain, dust, or smoke, adversely affect visibility or traction. Speed shall be reduced when such conditions exist. If conditions become sufficiently dangerous, the operation of the vehicle shall be discontinued and shall not be resumed until the vehicle can be safely operated." Standard procedures should be followed to hold shipments at safe-parking locations when severe weather conditions or adverse road conditions are encountered en route.

\subsection{STANDARD PROCEDURES}

Cs shipments will not travel when severe weather conditions along the route or adverse road conditions make travel hazardous. Upon encountering severe weather or adverse road conditions, the carrier should immediately contact the TCC.

Inclement weather conditions may not have forced a road closure, but create hazardous travel conditions or the possibility of an imminent road closure. Traffic accidents or other conditions may also create hazardous travel conditions that should be avoided by $\mathrm{Cs}$ shipments. In these cases, the State Highway Patrol, State Police, or CTUIR Tribal Police may notify the TCC that hazardous travel conditions exist and advise that the carrier should locate a safe parking area based upon the attached Safe Parking Criteria for ${ }^{137} \mathrm{Cs}$ Shipments (Appendix G) until permission to proceed is granted.

Upon indication of severe weather or adverse road conditions from the carrier or from any of the sources listed in Appendix F, Section 2.0, the TCC Operator shall notify the appropriate state contact listed in Table 2. If the indication of severe weather or adverse road conditions was not obtained from the carrier, the TCC Operator should also notify the carrier as soon as possible. The state contact will specify a safe-parking location and/or will provide guidance on the criteria to follow to select a safe-parking location. The TCC Operator will notify the carrier to proceed to a safe-parking location based upon the direction and/or guidance received from the state/tribal contact. 


\section{WHC-MK-0523, REV.O \\ CESIUM TRANSPORTATION PL.AN Rev. 0 June 1996}

The safe-parking area should be selected based upon the criteria specified in Appendix F, Section 4.0. If the safe-parking location was not selected by the state, the state or CTUIR contact listed in Table 1 for the affected state or CTUIR should be notified of the parking location selected. TCC should enter the safe-parking location in the Note Field of the Shipment Information Screen on TRANSCOM. The layover should continue until conditions clear, the route is passable, or proper mechanical repairs completed. In the event safe parking is requested by the state/tribal and/or carrier designate due to weather and/or road conditions, TCC should monitor the weather and road conditions using the sources 1 isted in Appendix F, Section 2.0. When it appears that conditions are acceptable, the TCC Operator should contact the state/tribal contact listed in Table 1 to request permission to release the shipment from the safe-parking location. Shipments will not be released until permission is received from the state- or CTUIR-designated contact.

Details of the conversations and decisions. will be entered into the TCC Operator's log.

\subsection{STATE AND CTUIR PROCEDURES}

The State Highway Patrol, State Police, or CTUIR Tribal Police for each jurisdiction will adopt appropriate procedures to implement the Procedures and Frotocols for Safe Parking Criteria for Cesium Shipments. State and CTUIR procedures should include:

- Procedures to provide TCC that weather and road conditions are unacceptable for a shipment prior to entering and/or delayed in that entities jurisdiction.

- Procedures to notify the TCC of adverse weather and/or road conditions that a shipment may encounter en route to or through its corridor.

- Procedures to evaluate the current and projected weather/road conditions and to respond to requests from TCC to allow a shipment to enter or leave a safe-parking location.

- Procedures to allow the shipment to proceed safely as soon as possible.

- State procedures sha 11 include criteria for selecting safe parking.

Designated points of contact for these procedures for each jurisdiction are identified in Appendix G.

\subsection{SAFE PARKING}

Shipments of Cs capsules to Hanford, Washington may be delayed en route due to mechanical problems, adverse weather conditions, bad road conditions, or other unanticipated problems. When a shipment is delayed en route, a safeparking location must be identified. The safe-parking location either will be specified by the state or CTUIR or will be selected by the carrier and/or DOE/WHC depending upon where the shipment is located. For jurisdictions where the carrier and/or DOE/WHC selects the parking location, a hierarchy has been developed to incorporate two factors: 1) the desirability of a particular 


\section{WHC-MR-0S23, POVO}

CESIUM TRANSPORTATION PLAN Rev. 0 June 1996

type of parking area; and 2) the carrier's ability to reach that parking area under different types of emergencies.

Table 3. Criteria for Selection of Parking Areas.

\begin{tabular}{|l|l|}
\hline First Choice & DOE and DOD facilities \\
\hline Second Choice & $\begin{array}{l}\text { Specific types of places possibly, but not necessarily, } \\
\text { predesignated by states (e.g., truck stops, state highway } \\
\text { department sheds, ports of entry, National Guard units) }\end{array}$ \\
\hline Third Choice & Factors to avoid: \\
& $\begin{array}{l}\text { - Highly populated areas } \\
\text { - Areas that are difficult to evacuate in case of } \\
\text { - Industrial areas (e.g., refineries) }\end{array}$ \\
& $\begin{array}{l}\text { - Areas with difficult access } \\
\text { - Parked trucks carrying flammables or explosives } \\
\text { - Poorly lighted areas } \\
\text { - Highway shoulders } \\
\text { Residential areas } \\
\text { - Areas with numerous pedestrians } \\
\text { Areas without driver services (e.g., food) }\end{array}$ \\
\hline
\end{tabular}

First Choice: DOE/DOD facilities are the most desirable parking areas for Cs shipments. However, it may not be possible for the carrier to safely reach a DOE/DOD facility. Decision makers should then proceed down the hierarchy in selecting a parking area.

Second Choice: Specific types of facilities are likely to be more common than DOE/DOD facilities. State-specific information on the types of facilities that are acceptable is listed below. If the carrier cannot reach one of these types of facilities, then the decision maker should use the Third Choice criteria.

Third Choice: If no DOD/DOE facilities or facilities listed in the second tier can be reached safely, a series of avoidance factors should be applied to select a parking area. No priorities have been assigned to these factors. It may not be possible to select a parking site that meets all of the criteria listed in the third tier. Compromises may be necessary based upon local conditions. 


\section{WHC-MR-0523. KEV.O \\ CESIUM TRANSPORTATION PLAN Rev. 0 June 1996}

The vehicle "must not be parked on or within five feet of the traveled portion of public street or highway except for brief periods when the necessities of operation require the vehicle to be parked and make it impracticable to park the vehicle in any other place" (49 CFR 397.7(b)).

Some jurisdictions have elected to develop procedures to specify the safe-parking location whenever a Cs shipment is delayed. Other jurisdictions have elected to have the carrier use the safe-parking criteria to select a parking location and notify the state of the location selected. Specific procedures for each jurisdiction are shown in Safe Parking Criteria for ${ }^{137} \mathrm{CS}$ Shipments (Appendix G).

\section{National Weather Service Terms Used in Advisories \\ Summer Conditions}

- Warning. Issued for tornadoes, severe thunderstorms, flash floods, river floods. A warning is issued when severe weather has already developed and has been reported by spotters or indicated by radar. Warnings are statements of imminent danger and are issued for relatively small areas and downstream from the severe storm or flood.

- Watch. Issued for tornadoes, severe thunderstorms, flash floods. A watch identifies a relatively large area in which flash floods or severe storms might occur. Watches are quite often issued before any severe weather has developed. Serve thunderstorm and tornado watches usually include an area 140 miles wide by about 200 miles long. The watch is only an indication of where and when the severe weather probabilities are highest, and should not be confused with a warning.

- Thunderstorm. A local storm (accompanied by lighting and thunder) produced by a cumulonimbus cloud, usually with gusty winds, heavy rain, and sometimes hail. Non-severe thunderstorms rarely have lifetimes over two hours.

- Severe Thunderstorm. A thunderstorm which may last for hours beyond the lifetime of a normal thunderstorm while producing large hail, high winds, torrential rain, and possible tornadoes. Officially, a thunderstorm is classified as severe if $58 \mathrm{mph}$ winds are measured, 0.75 -inch or larger hail occurs, or funnel clouds or tornadoes develop.

\section{Winds}

- High Wind Warning. Winds of at least $40 \mathrm{mph}$ are expected to 7 ast for at least one hour. (In some areas, this means strong gusty winds occurring in shorter time periods.) 
WHC- $M R-0523, K=6.0$

CESIUM TRANSPORTATION PLAN Rev. 0 June 1996

Terms Related to Winds ${ }^{1}$

Windy . . . . . . . . . . . 20-30 mph, gusts to $40 \mathrm{mph}$ Quite windy or very windy ....... 30-40 mph, gusts to $50 \mathrm{mph}$ Dangerous winds .......... 40-50 mph, gusts to $58 \mathrm{mph}$

Table 4. Wind Speeds.

\begin{tabular}{|c|c|}
\hline Wind speed (mph) & Indications \\
\hline $25-31$ & $\begin{array}{l}\text { Large branches in motion; whistling heard in telephone } \\
\text { wires }\end{array}$ \\
\hline $32-38$ & $\begin{array}{l}\text { Whole trees in motion; inconvenience felt walking } \\
\text { against wind }\end{array}$ \\
\hline $39-54$. & Twigs break off trees; wind generally impedes progress \\
\hline $55-72$ & $\begin{array}{l}\text { Damage to chimneys and TV antenna; pushes over shallow } \\
\text { rooted trees }\end{array}$ \\
\hline $73-112$ & $\begin{array}{l}\text { Peels surface off roofs; windows broken; } 1 \text { ight trailer } \\
\text { houses pushed or overturned; moving automobiles pushed } \\
\text { off roads }\end{array}$ \\
\hline $113-157$ & $\begin{array}{l}\text { Roofs torn off houses; weak buildings and trailer houses } \\
\text { destroyed; large trees snapped and uprooted }\end{array}$ \\
\hline $158 \&$ up & Severe damage; cars 1 ifted off ground \\
\hline
\end{tabular}

Adapted from the Beaufort and Fujita Wind scales

'National Weather Service Spotter's Guide for Identifying and Reporting Severe Local Storms, U.S. Department of Commerce, National Oceanic and Atmospheric Administration, National Weather Service, NOAA/PA 81011 (Rev. April 1982). 
WHC- MKR- 0523, KEV. 0

CESIUM TRANSPORTATION PLAN Rev. 0 June 1996

This page intentionally left blank. 
WHE- ME-OSo3, $K E V O$

CESIUM TRANSPORTATION PLAN

Rev. 0 June 1996

APPENDIX G: SAFE-PARKING CRITERIA FOR ${ }^{137}$ CS SHIPMENTS 
WHC-MK-0523, $1 E 1 / C$

CESIUM TRANSPORTATIOV PLAN Rev. 0 June 1996

VIRGINIA

Carrier and TCC should select safe-parking location based upon the following procedures:

State predesignated parking areas None

First choice for safe parking areas DOE/DOD facilities

DOE/DOD facilities designated as None

safe-parking areas

Second choice for safe-parking area NA

Third choice for safe-parking area Carrier selects safe-parking area based upon areas to avoid

Contact action

Carrier should call the VSP/DES

Contact telephone number

Virginia State Police, Duty Sergeant (804) 674-2026

Department of Emergency Services

(804) $674-2400$

Additional considerations

Public rest areas are not appropriate parking for $C_{s}$ shipments

Circumstances when route change would be preferable to parking

None 
WHC- $m K-0523, \mu V$.

CESIUM TRANSPORTATION PLAN Rev. 0 June 1996

WEST VIRGINIA

State pre-designated parking areas None

First choice for safe-parking areas DOE and DOD facilities

DOE and DOD facilities designated as "None Designated" safe-parking areas

First choice for safe-parking area

The West Virginia State Police will coordinate with appropriate state and local officials to determine those locations

second choice for safe-parking area Carrier selects safe-parking locations based on areas to avoid

Contact action The carrier should contact the West Virginia State Police at (304) 746-2158

Contact telephone numbers West Virginia State Police (304) $746-2158$

Additional considerations None

Circumstances when a route change None would be preferable to parking 
WHC- MK-OS23, KEV.O

CESIUM TRANSPORTATION PLAN Rev. 0 June 1996

\section{KENTUCKY}

State pre-designated parking areas None

First choice for safe-parking areas DOE/DOD facilities

DOE/DOD facilities designated as None

safe-parking areas

Second choice for safe-parking area None

Third choice for safe-parking area Carrier selects safe-parking areas based upon areas to avoid

Contact action

Carrier should call the Kentucky State Police and DES-0perations

Contact telephone numbers

DES-Operations (502) 564-7815

Division of Motor Vehicle Enforcement (502) 564-3276

Additional considerations

Parking at public rest areas shall only be in areas designated for trucks

Circumstances when route change None would be preferable to parking 
WHC-MR-0523, NEV. O

CESIUM TRANSPORTATION PLAN Rev. 0 June 1996

\section{INDIANA}

The state of Indiana prefers the following locations for safe-parking areas:

- Indiana State Police District Headquarters

- Weigh Scales and Inspection Stations

- Highway Department Sheds

- National Guard Armories

Refer back to page E2 (Contacts for Emergency Conditions) if a condition warrants Indiana to be contacted. 
WHC-mk-0.502, 61.6

CESIUM TRANSPORTATION PLAN Rev. 0 June 1996

\section{IL.LINIIS}

The Illinois Department of Transportation does not have a safe-parking criterion or list of safe-haven locations for radioactive shipments.

Refer back to page E2 (Contacts for Emergency Conditions) if a condition warrants 111 inois to be contacted. 
WHC-MR-0523, TEV O

CESIUM TRANSPORTATION PLAN Rev. 0 June 1996

IOWA

Carrier and TCC should select safe-parking location based upon the following procedures:

State predesignated parking areas None

First choice for safe parking areas DOE/DOD facilities

DOE/DOD facilities designated as None

safe-parking areas

Second choice for safe-parking area NA

Third choice for safe-parking area Carrier selects safe-parking area based upon areas to avoid

Contact action

Carrier should call the Iowa Department of Transportation/Motor Vehicle Division/Captain T. Sever

Contact telephone number

Iowa Department of Transportation/Motor Vehicle Division/Captain T. Sever

(515) 237-3160 (24 hr)

Additional considerations

Public rest areas are not appropriate parking for Cs shipments

Circumstances when route change None would be preferable to parking 
WHC-MK-0S23, KEV C

CESIUM TRANSPORTATION PLAN Rev. 0 June 1996

NEBRASKA

Carrier and TCC should select a safe-parking location based upon the following procedures:

State pre-designated parking areas

First choice for safe-parking areas

DOE/DOD facilities designated as

safe-parking areas

Second choice for safe-parking area

Third choice for safe-parking area

Contact action

Contact telephone number

Additional considerations

Circumstances when route change would be preferable to parking
None

DOE/DOD facilities

None

NA

Carrier selects safe-parking area based upon areas to avoid

Carrier should call the Nebraska State Police

State Police HQ (402) 471-4545

Public rest areas are not appropriate parking areas for CS shipments

None 
$\omega A C-m k-0523, r k 1$.

CESIUM TRANSPORTATION PLAN REV. 0 June 1996

WYOMING

NOTE: During road closures, truck stops become very congested. The potential for parking lot accident situations is increased. The carrier should check with Highway Patrol for possible better parking areas during road closure. Carrier and TCC should select a safe-parking location based upon the following procedures:

State pre-designated parking area

First choice for safe-parking area

DOE/DOD facilities designated as

safe-parking areas

Second choice for safe-parking area

Third choice for safe-parking area

Contact action

Contact telephone number

Additional considerations

Circumstances when route change would None be preferable to parking
None

DOE/DOD facilities

F. E. Warren AFB

Truck stops, ports of entry

Carrier selects safe-parking area based upon areas to avoid

Carrier should notify TCC of selected safe-parking area. Carrier should call the Wyoming Highway Patrol for concurrence and/or additional guidance during road closures if a problem selecting a safe-parking location arises, or if TRANSCOM is not working

(307) 777-4321

Public rest areas are not appropriate parking areas for $C s$ shipments. DOT yards will not be available for parking Cs shipments 


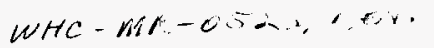

CESIUM TRANSPORTATION PLAN Rev. 0 June 1996

UTAH

Carrier and/or the TCC will notify the UHP. The parking site for all unscheduled stops will be selected using the list of pre-designated temporary safe-parking areas. Due to exigent circunstances, the carrier may be forced to temporarily use parking areas not. listed in the safe-parking plan. In that event, the UHP shall be notified of the location and conditions warranting the deviation from the designated safe-parking areas.

State pre-designated parking areas None

First choice for safe-parking area

DOE/DOD facilities designated as

safe-parking areas

Second choice for safe-parking area

Third choice for safe-parking area

Contact action

Contact telephone number

DOE/DOD facilities

Hill AFB, Utah Depot

Perry and Echo ports of entry, Snowville, Bothwel1, Riverside, and Echo Junction state maintenance facilities

Carrier selects safe-parking area based upon areas to avoid

Carrier should call the Utah

Department of Safety for concurrence and/or additional guidance

(801) 965-4505

Additional considerations

None

Circumstances when route change would be preferable to parking

In the event of a long-term road closure, an alternate route would be considered only after consultation with the Utah Highway Patrol and the Utah DOT 
WHC- $m K-052: 3,1 \in V_{1}$

CESIUM TRANSPORTATION PLAN Rev. O June 1996

IDAHD

The Idaho State Police will provide specific directions whenever a safe-parking location is required.

State pre-designated parking areas

DOE/DOD facilities designated as safe-parking areas

First choice for safe-parking areas

Second choice for safe-parking areas

Third choice for safe-parking areas

Contact telephone number

Additional considerations

Circumstances when route change would be preferable to parking
None

Mountain Home AFB

DOE/DOD facilities

Transportation Department Maintenance Yards, Ports of Entry, and National Guard Facilities

Driver select safe-parking area based upon areas to avoid.

Idaho State Police, Boise

(208) 334-2900

None

There are times when a route change with Idaho State Police escort would be preferable to parking 
WHC- MK-0523, KEV. O

CESIUM TRANSPORTATION PI.AN Rev. 0 June 1996

OREGON

following:

Carrier and TCC should select a safe parking location based upon the

State pre-designated parking areas

Farewe11/Bend port of entry, Umatilla port of entry

First choice for safe-parking area

DOE/DOD facilities

DOE/DOD facilities designated as

safe-parking areas

Second choice for safe-parking area

Umatilla Army Depot

Contact action

Umatilla port of entry, Farewell/Bend port of entry (near Ontario)

Carrier should notify the Oregon

Emergency Management Duty officer for concurrence and/or additional guidance

Contact telephone number

(503) 378-6377

Additional considerations

None

Circumstances when route change would be preferable to parking

If an accident is blocking the interstate and the police are re-routing other traffic, the Cs shipments should follow the rest of the traffic. The Oregon Emergency Management Duty officer should be notified of the deviation in the route 
wHe. mR-0523, $K \in V . C$

CESIUM TRANSPORTATION PLAN Rev. 0 June 1996

CONFEDERATED TRIBES OF THE UMATILLA INDIAN RESERVATION

Carrier and TCC should select a safe-parking location upon the following procedures:

CTUIR pre-designated safe-parking None areas

First choice for safe-parking areas

DOE/DOD facilities

DOE/DOD facilities designated as

safe-parking areas

Second choice for safe-parking area None

Third choice for safe-parking area

Carrier selects safe-parking area based upon areas to avoid

Contact action

Carrier should notify the CTUIR

Tribal Police for concurrence and/or additional guidance

Contact telephone number

(503) 278-0550

Additional considerations

Arrowhead Truck Plaza and Wild Horse Gaming Resort are not acceptable safe-parking locations

Circumstances when route change would None be preferable to parking 
$\omega / C-m R \cdot 0 \leqslant 23, k E V \cdot C$

CESIUM TRANSPORTATION PLAN ReV. 0 June 1996

\section{WASHINGTON}

The WSP will provide specific directions whenever a safe-parking location is required.

State pre-designated parking areas None

First choice for safe-parking areas DOE/DOD facilities

DOE/DOD facilities designated as RL

safe-parking areas

Second choice for safe-parking area

Plymouth port of entry

Third choice for safe-parking area

Carrier selects safe-parking area based upon areas to avoid

Contact action

Carrier should contact WSP Communications Center

Contact telephone number (509) 575-2323

Additional considerations

Circumstances when route change would be preferable to parking

New routes may be acceptable for long-term emergencies. During shortterm incidents/accidents, parking or limited detours may be utilized, depending upon the incident/accident 